\title{
Recent progress on polymer scaffolds production: Methods, main results, advantages and disadvantages
}

\author{
Thaís Larissa do Amaral Montanheiro ${ }^{*}{ }^{\mathbb{D}}$, Vanessa Modelski Schatkoski ${ }^{1 \mathbb{D}}$, \\ Beatriz Rossi Canuto de Menezes ${ }^{1}{ }^{\circledR}$, Raissa Monteiro Pereira ${ }^{1}{ }^{\circledR}$, Renata Guimarães Ribas $^{1}{ }^{(}$, \\ Amanda de Sousa Martinez de Freitas ${ }^{2 ®}$, Ana Paula Lemes ${ }^{2}$, \\ Maria Helena Figueira Vaz Fernandes ${ }^{30}$, Gilmar Patrocínio Thim ${ }^{10}$ \\ ${ }^{1}$ Laboratory of Plasmas and Processes (LPP), Technological Institute of Aeronautics (ITA), Praça Marechal Eduardo \\ Gomes, 50, Vila das Acácias, 12228-900 São José dos Campos, SP, Brazil \\ ${ }^{2}$ Polymers and Biopolymers Technology Lab. (TecPBio), Institute of Science and Technology (ICT), Federal University \\ of São Paulo (UNIFESP), 12231-280 São José do Campos, SP, Brazil \\ ${ }^{3}$ CICECO Laboratory, Materials Department, University of Aveiro, Aveiro, Portugal
}

Received 23 July 2021; accepted in revised form 1 October 2021

\begin{abstract}
Porous polymeric scaffolds provide a physical substrate for cells to attach and proliferate, allowing the formation of new tissue. These materials are broadly used in the tissue engineering field due to their ability to mimic native tissue. Each application requires specific morphologies and resistance, among other several features. To accomplish these requirements, various techniques are available, each one with its advantages and disadvantages. Among the most relevant techniques are salt leaching, solvent casting, gas foaming, thermally induced phase separation, freeze-drying, electrospinning, thermally induced self-agglomeration, and three-dimensional (3D) printing. In this review, a brief and simple explanation of each method is described, along with some recent results and each technique's advantages and disadvantages. It is expected that this review will bring important guidance in the production of polymer scaffolds for tissue engineering.
\end{abstract}

Keywords: biocompatible polymers, polymer scaffold, 3D scaffold, production techniques, tissue engineering

\section{Introduction}

Shortcomings related to tissue regeneration, including bone and soft tissue treatments, have directed efforts in the field of tissue engineering and regenerative medicine. 3D scaffolds are structural frameworks that may support cell organization and vascularization, elementary requirements for a tissue engineering strategy [1]. 3D structures for biological applications must present interconnected pores for diffusion and removal of essential nutrients, such as oxygen and wastes, as well as pore size adequate for each type of cell $[2,3]$.

Nowadays, the idea of reconstructing organs and tissues in the laboratory is widely disseminated and investigated worldwide. However, although many artificial prosthetic devices are available, only a few can completely replace the biological functions of the human body. The development of synthetic bone scaffolds as bone graft substitutes provides support for cell growth and additionally acts as a mechanical and structural substitute for the original tissue until the formation of the new tissue and the complete bio reabsorption of the scaffolds $[4,5]$. The regeneration of the skin after serious injuries like necrotic wounds, scabs, burns may be challenging without using a scaffold $[6,7]$. General treatment procedures, which include surgical and artificial implantation and drug therapy, are not satisfying in most cases because of

\footnotetext{
*Corresponding author, e-mail: tlamontanheiro@gmail.com
} (C) BME-PT 
tissue rejection, low grafting, immunological problems, limited donors, among others [8].

Different materials have been used as matrices for skin regeneration, and many multicomponent scaffolds with tunable features are emerging as promising candidates [9]. Synthetic and natural polymers have been widely studied as potential materials for the fabrication of porous scaffolds. Synthetic choices may have the advantage of tunable physical properties and biocompatibility; however, the vast majority shows a lack of antimicrobial properties, which may lead to an infection at the implantation site [10]. The choice of a natural polymer favors bioactivity with the extracellular matrix of native tissues [11]. Biodegradable and biocompatible polymers have some advantages for scaffolds application since they metabolize into biocompatible degradation products in the human body. Biodegradable polymer scaffolds serve as temporary templates and present time as the fourth dimension for tissue regeneration [12]. In this way, a second surgery for implant removal is unnecessary [13].

One of the major challenges in the production of a scaffold is obtaining an appropriate equilibrium between porosity and compression strength [14]. It is well known that reducing porosity leads to thicker pore walls, consequently improving mechanical properties [6]. Macropores allow the diffusion of waste and nutrients, while micropores are responsible for capillary, vascularization, and cell-matrix interactions [15], thus changing the porosity is also possible to tailor the cell growth within the scaffold [16].

Within this context, several methods have been developed to prepare porous scaffolds with interconnected open pores and suitable porosity to allow sufficient transport of nutrients and facilitate multicellular processes. Each method has its advantages and limitations and may be appropriate for producing a specific scaffold. In this review, the main cited methods for obtaining porous polymer scaffolds are reported, as well as their advantages and disadvantages, along with a brief and clear explanation of the relevant steps in each technique.

\section{Polymer scaffolds production \\ 2.1. Salt leaching}

Salt leaching has been presented as an easy and viable technique to produce scaffolds for tissue engineering when compared to other traditional methods. This technique consists in adding salt to a polymeric matrix and subsequently promote its leaching. The porous material is created when the composite (polymer matrix and salt) is leached for removing through dissolution the salt particles (porogen). The leaching process may be completed in a short time (approximately 48 hours in many situations) and produces substrates with approximately $70-90 \%$ porosity, depending on the amount of salt added [5]. The pore diameter can be controlled by the size of the salt crystals, allowing pore interconnection and resulting in a very reproducible technique. However, this method has some disadvantages; for example, some degradation may occur when the material is exposed to water, and it is difficult to guarantee the complete removal of salt from samples [5, 17]. Another shortcoming of this method is that it only allows the production of samples up to $3 \mathrm{~mm}$ thick [18]; besides that, sizes, dimensions, and shapes are limited by the mold in which the system polymer salt was poured. However, complex shapes are not indicated, once the evaporation of the solvent and complete removal of soluble particles inside the scaffold will be harmed. The most common leachable slat porogen is sodium chloride $(\mathrm{NaCl})[5,17]$ due to its high solubility in water. However, other salts have been studied, such as copper sulfate $\left(\mathrm{Cu}_{2} \mathrm{SO}_{4}\right)$ [4] and ammonium carbonate $\left(\left(\mathrm{NH}_{4}\right)_{2} \mathrm{CO}_{3}\right)[19]$ or organic particles such as sucrose. The salt leaching method has been used exclusively or combined with other techniques (e.g. 3D printing and solvent casting) to cartilage [20] and bone tissue engineering $[5,17]$. Figure 1a shows the simplified scheme of a typical salt leaching process. $\mathrm{NaCl}$ crystals were used as a porogen to prepare poly(D, L-lactide) (PDLLA) scaffolds and PDLLA with doped-bioactive glasses. $\mathrm{NaCl}$ was added to the polymer in a weight ratio of 9:1. PDLLA composite was lyophilized to remove the solvent (dimethyl carbonate), and subsequent porogen leaching was performed for $48 \mathrm{~h}$ to completely dissolve the salt crystals and leave a porous structure. All the scaffolds prepared showed high porosity ( $\sim 93 \%$ ) and regularly connected pores ranging from 100 to $400 \mu \mathrm{m}$. The elastic modulus exhibited by the prepared composite scaffolds showed a maximum value of $5.3 \mathrm{kPa}$, which would be suitable for low-load-bearing applications. After the simulated body fluid (SBF) assays, the X-ray diffractogram (XRD) showed peaks related to the formation of hydroxyapatite (HA) in addition to peaks related to the $\mathrm{NaCl}$ phase. However, the $\mathrm{NaCl}$ phase showed progressive dissolution with 
the immersion time, and no reduction in bioactivity was attributed to the presence of this phase. The ability to maintain the porous structure and mechanical properties during the generation of the cellular matrix and mineralization process is desirable. In this way, degradation studies in phosphate buffer solution (PBS) showed that the scaffolds lost almost 10\% of their initial weights after 120 days of immersion [17]. In vitro tests performed in a previous study [21] showed cytocompatibility of the scaffolds against bone marrow stromal cells (ST-2), and its good angiogenic and osteogenic properties. Thus, the study showed a broad analysis regarding the physicalchemical and biological behavior of the material. Nonetheless, the possible surface interaction of the host with graft is a critical parameter that should be regarded in vivo assays once is difficult to reproduce in vitro the same microenvironment found in vivo, such as $\mathrm{pH}$ gradients, the presence of other cells, biological molecules, proteins, and other ionic species.

The salt leaching powder method (salt leaching using powder - SLUP) was employed to fabricate bioglasschitosan (CS) composite scaffolds with improved pore interconnectivity [5]. $\mathrm{NaCl}$ crystals were used as porogen and were mixed with 46S6 bioactive glass, producing a composite powder granule that was subsequently dispersed in CS. The produced scaffold exhibited a porosity of $90 \%$ and a regular porous structure (average pore size around $30 \mu \mathrm{m}$ ) with an interconnected network that is ideal for the vascularization process. XRD analysis did not show peaks corresponding to the $\mathrm{NaCl}$ phase. Furthermore, the HA formations after being soaked in SBF confirmed the high bioactivity of SLUP scaffolds. The porous structure facilitated the bioglass dissolution, increasing the ion exchanges and consequently improving the bioactivity [5]. The study highlights the use of the SLUP technique to produce porous scaffolds with interconnected porous. However, it shows a preliminary study according to physical-chemical properties but does not show important characterizations such as degradation and mechanical strength. Despite different researches show the promising use of this type of 4S6S-chitosan composite scaffolds for biomedical applications [22-24], in vivo and in vitro studies are needed to validate the material produced for its intended use.

The salt leaching method could be associated with other techniques to produce scaffolds. The 3D printing process was combined with traditional salt-leaching to produce porous scaffolds of polylactide- $\mathrm{co}$-glycolide (PLGA) [4]. The inks were produced using different volume ratios of $\mathrm{Cu}_{2} \mathrm{SO}_{4}$ salt ( 25 to $70 \mathrm{wt} \%$ ) to PLGA. Initially, $\mathrm{Cu}_{2} \mathrm{SO}_{4}$ powders were sieved through 325 mesh to remove large particles and agglomerates, mitigating the possibility of nozzle clogging during $3 \mathrm{D}$ printing. The $\mathrm{Cu}_{2} \mathrm{SO}_{4}$ particles were dispersed in a mixture (dichloromethane, 2-butoxyethanol, and dibutyl phthalate), with previously dissolved PLGA. After the 3D printing step, residual salt and organic solvents were removed with water and ethanol. Finally, the material was lyophilized, resulting in a highly porous (66.6-94.4\%) PLGA framework (F-PLGA). The $\mathrm{Cu}_{2} \mathrm{SO}_{4}$ is highly soluble in water and, in an aqueous medium, changes the color from off-white to blue, facilitating the identification of the progress and degree of salt removal from the 3D-printed material. The sample with $25 \%$ of $\mathrm{Cu}_{2} \mathrm{SO}_{4}$ (25F-PLGA) retained a light blue color after leaching, indicating that a certain amount of $\mathrm{Cu}^{2+}$ is retained within the PLGA matrix, which was confirmed in a $\mathrm{Cu}^{2+}$ assay, and was harmful to human mesenchymal stem cells (hMSCs). An important parameter observed was the order of the washing process (ethanol first or water first), which affected the rate of $\mathrm{Cu}_{2} \mathrm{SO}_{4}$ dissolution. Washing the samples in $70 \%$ ethanol first resulted in faster leaching of $\mathrm{Cu}_{2} \mathrm{SO}_{4}$. Mechanical tests conducted in a hydrated state resulted in elastic moduli ranging from 112.6 to $2.7 \mathrm{MPa}$ for $25 \mathrm{~F}-\mathrm{PLGA}$ and $70 \mathrm{~F}-\mathrm{PLGA}$, respectively. In vitro tests against hMSCs cells showed that 50 and 70 F-PLGA samples promoted stem cell adhesion and proliferation [4]. The study highlighted the possibility of fabricating structures with substantial porosity through the purely physical salt-printing and leaching processes. The produced 3D-printed structures showed good mechanical properties being suitable for surgical manipulations and could act as carriers through its filling with active liquids and gels. However, 3D printing has some drawbacks, including the difficulty to mismatch tissue and organ interfaces from in vitro fabrication to in vivo application besides long processing times, and postprocessing manipulation, such as chemical and photochemical crosslinking and associated additives (such as dibutyl phthalate) that may not be biocompatible in vivo [25].

The literature shows that the salt leaching fabrication process directly influences the morphologies and properties of the resulting scaffolds and allows the 
production of structures with good reproducibility and controlled porosity.

\subsection{Solvent casting}

In the solvent casting method, the polymer is dissolved with a suitable solvent, and the mixture is then poured into a mold with the desired shape. Different methods of drying can be applied to remove the solvent, including air drying, vacuum drying, and freeze-drying [26]. During the polymer dissolution step, it is possible to add water-soluble inorganic particles (e.g. $\mathrm{NaCl})$ or organic particles (e.g. sucrose) to obtain a porous structure after releasing the porogen. In this case, the process is reported as a solvent cast-salt leaching technique. The solvent casting method has been used to create scaffolds for soft tissue replacements [27, 28], packaging materials [2931], and bone tissue engineering when combined with the salt leaching technique [32]. Figure $1 \mathrm{~b}$ shows the simplified scheme of a solvent casting process.

The production of scaffolds must consider the type of tissue that will be reconstituted, its mechanical and morphological requirements. From this information, the most suitable materials for the given application are defined, as well as the process by which the raw material will be submitted for the formation of such a structure. Furthermore, the disadvantages of each technique must also be considered for choosing the best production technique. For example, the solvent casting technique presents as a major drawback, the permanence of residual organic solvents in the material. So, the production is limited to produce structures with a small thickness (up to $3 \mathrm{~mm}$ ) to facilitate the removal of the solvent [33]. The same occurs for the salt leaching technique since more complex geometries and thicker structures make the leaching process inside the scaffolds difficult.

The surface properties of the films prepared by solvent casting depend on the nature of the solvent that is used. The effect of different solvents on the pore size distribution of the polycaprolactone (PCL) thin films was studied [26]. The PCL films were made by dissolving PCL in chloroform (CL), methylene chloride $(\mathrm{MC})$, and three different compositions of dimethylformamide (DMF)/MC. The films prepared with three different combinations of MC and DMF resulted in porous structures, while the films prepared from CL and MC were not porous. The porogen properties of the solvents are related to solubility parameters and polarity between the polymer and solvent. Therefore, the non-porogen properties of CL and $\mathrm{MC}$ were assigned to good miscibility between PCL and CL and low boiling point of MC, respectively, once a solvent must have a high boiling point to be considered porogen [26]. This is a preliminary study focused on producing materials for tissue engineering. The study focuses only on the ability of some solvents to form pores in films produced by solvent casting. Besides chemical-physical characterization (FT-IR or gas chromatography, for example) to confirm the total solvent removal from the films, in vitro analysis are necessary to ensure possible in vivo applications.

The solvent cast-salt leaching technique is the most mentioned method to produce thick films (3D structures). Scaffolds of PCL and HA were produced by solvent cast-salt leaching method, using dichloromethane as the solvent and the porogen particle was $\mathrm{NaCl}$ [34]. A suspension containing PCL, HA, and $\mathrm{NaCl}$ was poured into a petri dish to evaporate the solvent. After $24 \mathrm{~h}$, the composite was washed with demineralized water to completely dissolve the salt and form a porous membrane (PCL/HA). Macro and micro interconnected pores could be observed by scanning electron microscopy (SEM) images. Mechanical tensile tests showed a maximum value of Young's modulus equal to $3.00 \mathrm{MPa}$ with $14.61 \%$ of elongation at break. In vitro tests carried out using smooth muscle cells (SMC) and L929 fibroblastic cells did not show a cytotoxic effect [34]. Despite having compatibility, no in vitro assay to evaluate osteogenesis and angiogenesis has been reported. However, the possibility of relating two relatively simple techniques for the manufacture of porous scaffolds with good mechanical properties and excellent biocompatibility is very attractive.

A polymer blend composed of poly(ester-ether urethane urea) (PEEUU) with PCL was synthesized for cardiac tissue regeneration by solvent casting (SCPEEUU-PCL) and solvent casting/salt leaching (SLPEEUU-PCL) methods to evaluate which technique would present the best results for the desired application [28]. The use of the salt leaching technique combined with the solvent cast improved the porosity from 51 to $90 \%$. The SL-PEEUU-PCL had larger pore sizes, containing mainly interconnected and opened pores with sizes ranging from $77-190 \mu \mathrm{m}$, which are suitable for cardiac tissue engineering. Besides that, the addition of $\mathrm{NaCl}$ severely reduced the stiffness of the scaffolds, which is appropriate once 
a very stiff matrix inhibits the growth and function of cardiac cells. However, the elasticity of the blend films enhanced with the increase in the PCL content from 0.62 to $63.3 \mathrm{MPa}$ for pure PEEUU and PEEUU/ PCL weight ratio of 50:50, respectively. In vitro assays showed high rates of cell viability and metabolic activity against $\mathrm{H} 9 \mathrm{c} 2$ cardiomyoblasts for polymer blends. Biodegradation rate and in vivo tissue response to the PEEUU, blends, and PCL films were carried out in male Wistar rats by subcutaneous implantation of the scaffolds. The results showed an appropriate interaction with the surrounding tissue and revealed that PEEUU-PCL blends degraded faster than pure PEEUU and PCL films [28]. This is a detailed study focused on myocardial tissue engineering. The authors investigated the behavior of the films produced according to the main characteristics necessary for the desired application, such as biocompatibility, ability to foster cells, degradation rate, and mechanical properties.

Our research group produced PCL films with 0.1, 0.5 , and $1.0 \mathrm{wt} \%$ of silver vanadate $\beta-\mathrm{AgVO}_{3}(\mathrm{SV})$ by solvent casting to be used as antimicrobial biomaterial [35]. SV particles were well dispersed and with good interfacial interaction with the PCL matrix. Antimicrobial activity was evaluated against Staphylococcus aureus and Escherichia coli by the agar diffusion method and by direct contact test. Nanocomposite produced with $1 \mathrm{wt} \%$ of SV into PCL showed antibacterial activity against $S$. aureus in the direct contact test. This was a preliminary study, once there was no report concerning the addition of SV into PCL. However, to be used as a scaffold, the morphology must be adjusted to porous, and cell viability and cytotoxicity need to be studied.

The solvent cast technique is a simple method to produce thin films. Also, it can be easily combined with other techniques aiming to produce materials for different applications, including scaffolds for hard tissue engineering. Furthermore, the choice of an appropriate solvent to the polymer or blend is very important to obtain the expected result. Various research groups have applied this technique to fabricate scaffolds with a wide range of properties. However, during solvent evaporation, the pore sizes vary and, in most cases, are not fully interconnected. In this way, the use of the salt leaching technique combined with solvent casting is a promising and viable alternative.

\subsection{Gas foaming}

Among the different methods of scaffolds preparation, gas foaming is one of the most traditionally used. This solvent-free technique consists of saturating a solid phase (polymer or polymer-based composite) with a gas phase (blowing agent), such as carbon dioxide $\left(\mathrm{CO}_{2}\right)$ and nitrogen $\left(\mathrm{N}_{2}\right)$, in high pressures [36-38]. Solid polymeric disks are exposed to a highpressure gas at controlled temperature and get saturated with the gas. The solubility is then swiftly decreased when the pressure is reduced to atmospheric levels, which creates a thermodynamic disequilibrium for the dissolved gas and consequently produces the nucleation and growth of gas bubbles inside the polymeric matrix [39]. Figure 1c shows a schematic representation of the gas foaming process.

$\mathrm{CO}_{2}$ is usually approved in the gas foaming process due to its non-toxicity, non-flammability, chemical stability, and less demanding supercritical conditions (critical temperature $=31^{\circ} \mathrm{C}$ and pressure $=$ $7.38 \mathrm{MPa}$ ) [40]. $\mathrm{CO}_{2}$ interacts with different polymers, even at low pressures, and contributes to plasticization. The gas foaming methodology, however, has a limitation concerning the polymer precursor, once crystalline polymers do not form foams. Besides that, it is necessary to have glass transition $\left(T_{\mathrm{g}}\right)$ and melting $\left(T_{\mathrm{m}}\right)$ temperatures compatible with the parameters of the gas used in the process.

Scaffolds of poly(propylene carbonate) (PPC) blended with starch and bioglass particles were fabricated by the gas foaming method [3]. The silicon-based bioglass was used to improve osseointegration, which

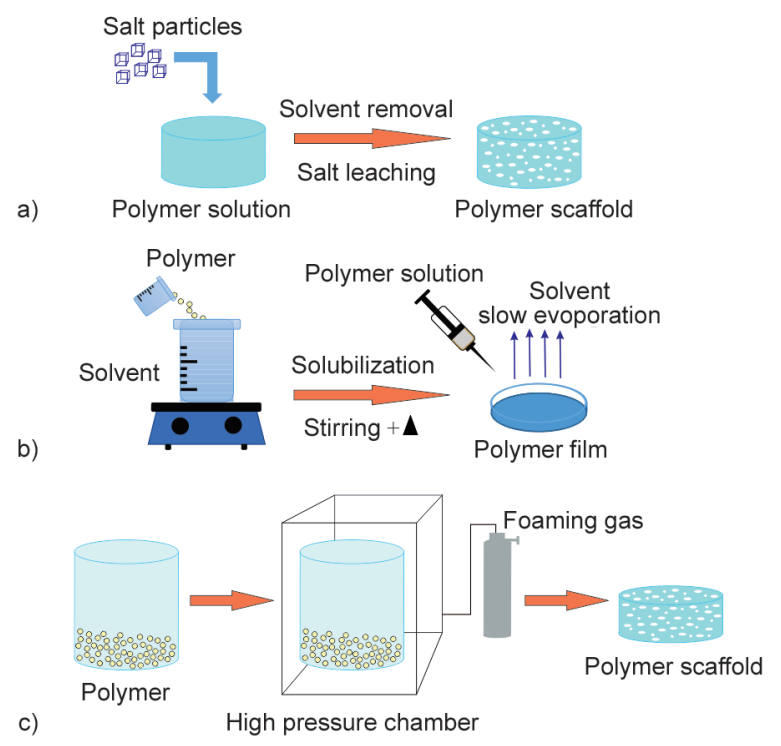

Figure 1. Simplified scheme of (a) salt leaching, (b) solvent casting, and (c) gas foaming methodologies. 
is important for bone regeneration applications. They compared scaffolds made under sub- and supercritical conditions, optimizing porosity, pore size, pore interconnectivity, and mechanical properties. At subcritical conditions (50 bar), they figured out that the effect of $\mathrm{CO}_{2}$ on polymer plasticization was inferior to that observed in scaffolds formed under supercritical conditions. This occurrence was attributed to the lower solubility in the polymer phase. This phenomenon is thermodynamically explained by the fact that the supercritical fluid serves as a plasticizer and decreases the polymer glass transition and/or melting temperature to generate porosity inside the constructs. The supercritical $\mathrm{CO}_{2}\left(\mathrm{scCO}_{2}\right)$ technique shows many advantages, among them: non-toxicity, porous structure (compatible with cellular matrix), and suitable mechanical properties. These features are favorable to cell compatibility, cell migration, nutrient transportation, and consequently, cell survival. Porosity and pore size increased with the increase of pressure, which leads to an expected reduction in the compressive modulus [3]. This investigation was properly carried out, covering physical and biological characterization, both in vitro and in vivo. Recent studies proved that the gas foaming technique permits controlling porous characteristics, resulting in scaffolds with promising in vivo and in vitro behavior $[2,3]$.

Porous structures of poly(L-lactic acid) (PLLA)/ poly(ethylene glycol) (PEG) with good strength $\left(11.9 \mathrm{MPa} /\left(\mathrm{g} \cdot \mathrm{cm}^{3}\right)\right)$ and interconnected pores $(90.3 \%)$ were prepared using $\mathrm{ScCO}_{2}$ as gas foaming [2]. The low melt strength and slow crystallization rate limit the formation of a uniform and porous structure of pure PLLA scaffolds. Then, to overcome these drawbacks, PEG was used (5\%) to improve foaming ability and achieve good pore morphology. The structured PLLA/PEG foam enhanced rabbit bone repair presented good compressive properties and interconnected porous structure [2]. This paper presented a very detailed methodology to obtain scaffolds using gas foaming, including in vitro and in vivo assays. In vitro biocompatibility analysis used fibroblast cells. Nevertheless, it would be interesting to perform the same analysis using different types of cells, such as mesenchymal, to investigate if the material has any influence on differentiation or even in osteoblasts since the aim of the work is for bone regeneration. Polymerase chain reaction (PCR) analysis would be very interesting to complement this study by giving information about gene expression and helping to understand the biological response of the studied cells. An advantageous aspect of the gas foaming technique is its capacity to design the pores features by adjusting the process. The gas $\left(\mathrm{scCO}_{2}\right)$ foaming parameters were adjusted to optimize the porous structure, and mechanical strength of PCL/poly(lactic acid) (PLA) blends scaffolds [41]. The authors observed the influence of foaming temperature on pore morphologies. Increasing the temperature, the viscosity and melt strength of the polymer decreased progressively, which intensified the mobility of chains, facilitating the pore growth. Consequently, the diameter of pores increases and the probability of merge or collapse raises, resulting in a gradual enhance of pore diameter distribution. However, the solubility of $\mathrm{CO}_{2}$ in polymer decreases, and the number of nucleation points reduces, entailing in lower cell density. When the pressure was raised, the dissolution of $\mathrm{CO}_{2}$ in the polymer increased, and the volume free energy is reduced. Hence, the nucleation efficiency and cell density increased, but the average diameter of cells was reduced. The authors observed that dissolution time, besides pressure and temperature, also influenced the morphology and porosity of polymer scaffolds [41]. Although authors presented a complete and extended mechanical and physical characterization, in vitro and in vivo assays are necessary for future studies.

Controlling the temperature and using two-step depressurization of $\mathrm{scCO}_{2}$, a bimodal open pores poly (butylene succinate)/cellulose nanocrystal (CNC) composite scaffold was fabricated [42]. The CNCs were used to reinforce the strength, improve the hydrophilicity and degradation rate of the composite scaffold. In the first pressure drop, few nucleation points were formed and began to grow. When the second pressure drop occurred, new points of nucleation appeared, while the previous bubbles formed already presented a significant volume. Therefore, scaffolds with two distinct average pore sizes could be obtained. The second pore nucleation and growth took place close to the large pore in the second depressurization due to the increase of free energy in the liquid-gas phase, leading to a highly interconnected and open porous architecture. Scaffolds also showed improvement in hydrophilicity and degradation rates, because of the increment of $\mathrm{CNC}$, besides an enhanced compressive strength and an excellent in vitro biocompatibility [42]. The authors fabricated a 
bimodal open-porous poly(butylene succinate)/CNC composite scaffolds for tissue engineering application and performed an elaborated characterization. However, more studies concerning in vivo studies are still necessary to determine the scaffold response in biological systems.

Another study developed a bimodal structure of poly (vinyl alcohol) (PVA)/PEG scaffold for tissue engineering [40]. As aforementioned, the hierarchical pore structure is critical in seeding and cell adhesion, as well as the interconnected network, which permits an easy diffusion of nutrients and wastes in the cellular cycle. The authors effectively adjusted the cellular structure of a PVA/PEG scaffold modifying the concentration of PEG or the molecular weight of this polymer. Thus, when the $\mathrm{scCO}_{2}$ was injected in composites with high PEG concentration or highmolecular-weight PEG, 'sea-island' structures were formed because of the immiscibility between the polymers. Moreover, as the PEG contains ether groups that have an affinity with $\mathrm{CO}_{2}$, the solubility and diffusivity of $\mathrm{CO}_{2}$ are superior in PEG (island phase) than in PVA (sea phase). In the depressurization step, more but smaller cells (with a tubular structure) were formed in the PVA phase. This tubular morphology is beneficial to orient cell growth and extracellular matrix deposition [40]. Yet, as the aforementioned papers, in vivo tests need to be performed to continue the study for human application in the future.

The main disadvantages associated with the gas foaming technique are related to the precursor polymer and the gas used. For a successful procedure, the use of polymer with appropriate crystallinity and good thermoplastic foaming is necessary. Additionally, the gas utilized must be non-toxic, no-inflammable, and exhibit good solubilization and diffusion in the polymer matrix. Most recent works use $\mathrm{scCO}_{2}$ because of these superior characteristics. Moreover, this technique demands that all operations need to be performed within a very short time because of the limited kinetic stability. Another drawback is related to sample size that limits their use for some practical purposes [43]. In certain applications, such as the production of cell culture substrates, the volume required is limited, of the order of $1 \mathrm{ml}$. The high pressures necessary to solubilize the gas in the solid restrain the scaffolds' total final volume, being the dimensions usually in the order of millimeters [2, 40, 42, 43].

In conclusion, when an adequate polymer that shows $T_{\mathrm{g}}$ and $T_{\mathrm{m}}$ compatible with appropriate parameters of the gas is applied, the gas foaming technique can be widely used to fabricate scaffolds. In the future, new investigations of how to control the pores tailoring the parameters involved in the scaffold development still need to be carried out. In this concern, new techniques have been studied to better control the pore size and morphology, such as the use of microfluidic foaming instead of solid disks [43]. Nevertheless, the simplicity, non-toxicity, solvent-free, lowcost, and high capacity to tailor pores morphology and distribution makes gas foaming a good approach to fabricate interconnected porous scaffolds for tissue engineering application.

\subsection{Thermally induced phase separation (TIPS) and freeze drying}

The techniques of TIPS and freeze-drying showed in Figure 2, are very similar to each other, as they are based on the freezing of the sample and subsequent extraction of the solvent used. As they do not use heat in the 'drying' process of the material produced, the original architecture is preserved, such as the porous structures, which are widely desired in the production of polymeric scaffolds.

The process known as TIPS, Figure 2a is based on three distinct steps. The first step is the solubilization of the polymer in a latent solvent, which consists of a solvent with a high boiling point that solubilizes the polymer at high temperatures, but at low temperatures works as a non-solvent [44]. In the second stage, after the complete dissolution of the polymer, the homogeneous mixture must be frozen to induce phase separation. The phase separation can occur in liquid-liquid or solid-liquid systems, and the pore morphology is formed at this stage based on thermodynamic principles, such as solution concentration, solution temperature, and cooling rate [45].

The third and last step consists of removing the latent solvent from the frozen sample. The polymer encased by the solvent must be sufficiently rigid to prevent the collapse of the pores to preserve the material structure since the solvent is removed from the sample by sublimation. Only dry samples with porous architectures remain after all solvent is removed. The porous architectures are formed by the spaces left by solvent, along with the channels formed during the sublimation step. Some parameters directly influence the pore morphology, such as the cooling mode, the molecular mass, the polymer concentration, and the solvent composition [46]. 
The polymeric scaffolds prepared by TIPS have the advantages of producing structures with different morphologies by changing the temperature and the cooling gradient [47], without the need for complex technological resources $[48,49]$. The production of large numbers of samples and the demand for few processing steps are also advantages when compared with salt leaching, for example [50]. The production of polymeric scaffolds by the TIPS technique is performed using a large range of adjustable parameters, which makes it possible to obtain materials with different pore sizes and structural requirements. These characteristics are useful in the tissue engineering field [47]. However, like any other methodology, TIPS has some disadvantages, as the use of organic solvents and high-energy consumption to obtain the samples [48-51].

Figure $2 b$ illustrates the freeze-drying or lyophilization process. This process can be used to remove the solvent from a system which structure must be preserved [51, 52]. The method initially consists of a drying step of the material and a later sublimation step of the solvent. The sample must be previously emulsified and frozen to keep the pores formation during the lyophilization step. Subsequently, the samples are exposed to a system that acts with a combination of vacuum and low temperatures to promote sublimation of the most diverse solvents without disintegration or structural collapse [46].

The temperature for solvent elimination must be low enough so that the polymer-rich region does not dissolve, allowing the original structure to be fully preserved as the removal takes place. The lyophilization process also allows drying biological samples, without the occurrence of denaturation [51], which is a

a)

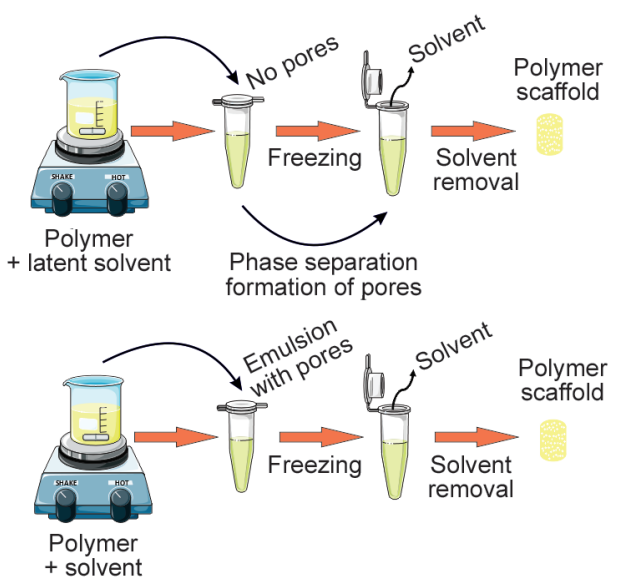

Figure 2. Simplified scheme of (a) TIPS and (b) freeze-drying methodologies. limitation in other widespread methods such as the evaporation of solvents and the injection of gases that demand higher temperatures. The production of porous $3 \mathrm{D}$ scaffolds with high porosity (greater than $90 \%$ ) and pore sizes ranging from 20 to $400 \mu \mathrm{m}$ is also an advantage of the lyophilization process. Another benefit of this method is the extensive range of solvents that can be used [53,54]. The disadvantages of the freeze-drying method are that it can only be performed with a limited group of polymers, and usually requires the use of cytotoxic organic solvents. Is a time-consuming production, which makes it economically uncompetitive. Besides that, samples produced are subjected to suffer shrinkage [46, 51, 5355]. These characteristics make the method widely used in the production of polymeric scaffolds for application in several areas, such as high porosity fabrics [56], on bone mesenchymal stem cell compatibility [57], and in locally-oriented tissues as a guide for chondrocyte fixation and dissemination [50].

The two techniques consist of similar basic principles and lead to porous structure formation. However, in TIPS, a solution with the polymer and the latent solvent is prepared under heating, and when cooled, there is phase separation, leading to the formation of pores. In freeze-drying, basically, the same process occurs, but with an emulsion that, when frozen, already has a porous structure that is preserved after the drying step.

Through the techniques of TIPS and freeze-drying, it is possible to produce scaffolds with 3D structure and various shapes; however, the limitation in the format and size is that the scaffold will have the shape of the container in which it was produced. Therefore, the range of sizes and shapes is restricted to the mold where the solution was frozen and to the size of the equipment where the sample will be frozen and have the solvent removed [55].

The TIPS method was used for the preparation of PLLA/PLGA/poly(L-lactide-co- $\varepsilon$-caprolactone) (PLLA/PLGA/PLCL) scaffolds, with various weight ratios and dissolved in tetrahydrofuran (THF) [52]. Subsequently, the vascular structure was superficially modified using heparin and stromal cell-derived factor-1 alpha (SDF-1 $\alpha$ ). Porous scaffolds were obtained, and the results showed that the incorporation of PLGA improved the hydrophilicity of the compound scaffolds. The heparin modification significantly increased anticoagulation, while the modification with SDF- $1 \alpha$ accelerated the migration and 
proliferation of mature endothelial cells and increased the recruitment of endothelial progenitor cells (EPCs), thus accelerating the endothelization of the modified vascular system. In addition, the modification with heparin and SDF-1 $\alpha$ inhibited the proliferation of human vascular SMC. This alteration can be an effective modifier of the vascular graft to increase anticoagulation and rapid endothelialization, presenting promising in vitro performance as a functional vascular graft small-diameter [52]. Besides showing proper in vitro results, as the authors used THF to solubilize the polymers, it would be important to evaluate the presence of residual solvent, and in vivo behavior should also be analyzed.

The TIPS method also was used to obtain a porous 3D PCL framework with potential for application in the repair of large bone defects [58]. For that, various PCL masses were solubilized in 90\% 1,4-dioxane/ water at $40^{\circ} \mathrm{C}$. The solutions were conditioned for 4 hours in an ice bath, aiming at phase separation. Subsequently, the samples were frozen and lyophilized. The porous structure was obtained without using any specific porogen agent or instruments. The variation in the concentration of the polymer was used to control the formation of macro and micropores, adjusting the porosity. The process formed structures like nanofibers, which was attributed to liquid-liquid separation and posterior nucleation and crystallization growth in the polymer-rich phase. The structural hierarchy improved the bioactivity, allowing the deposit and delivery of osteoinductive drugs. The sustained release, in addition to the high mechanical properties improved the protein BMP2-induced osteogenic differentiation. The adjustment of mechanical properties was also affected by the concentration of polymer, resulting in frameworks with potential for application in bone tissue engineering. It is noteworthy that the affinity-based drug release strategy is an advantageous method when compared to other methods that require, for example, the use of toxic chemicals and aggressive processes. Thus, the scaffolds developed would have the ability to sustain the release of several types of drugs, with bioactivity after the scaffolding release, acting synergistically to improve osteogenic differentiation. As mentioned before, it is important to evaluate the presence of residual solvent in the scaffolds and would be interesting to evaluate the results with bigger populational sizes $(n)$ to confirm the results.
In our research group, we employed TIPS to produce poly(3-hydroxybutyrate-co-3-hydroxyvalerate) (PHBV) scaffolds reinforced with CNC [6,9]. In the first report [6], we used 1, 2, and $3 \mathrm{wt} \%$ of pristine $\mathrm{CNC}$ into the scaffolds, and obtained porosity between 41 and $77 \%$ with interconnected pores with sizes ranging from 0.5 to $672 \mu \mathrm{m}$ for all samples, being that about $50 \%$ of the sizes were from 168 and $336 \mu \mathrm{m}$. The addition of $\mathrm{CNC}$ reduced the porosity and increased the mechanical compressive modulus, as well as the NIH-3T3 mouse fibroblast proliferation. For the second report, we evaluated the water uptake of PHBV scaffolds with the addition of acetylated and pegylated CNC (CNC-Ac and CNC-PEG). The addition of functionalized $\mathrm{CNC}$ also reduced the porosity and increased the mechanical compressive modulus of the scaffolds. However, even with lower porosity, the water uptake was increased with the addition of CNC-Ac (16\%) and CNC-PEG (67\%), compared to the neat PHBV scaffold. In this way, we showed that adding $\mathrm{CNC}$ to the scaffolds is an effective way to improve mechanical properties, without harming the diffusion of water inside the scaffold and improving cell proliferation. PHBV/ $\mathrm{CNC}$ scaffolds ate attractive alternatives for tissue engineering.

The lyophilization technique was used [59] for the preparation of conductive polymeric scaffolds of poly(3,4-ethylenedioxythiophene) (PEDOT) and xanthan gum. In this work, the authors combined the electrical conductivity of PEDOT, and the mechanical support and biocompatibility of xanthan gum, with the ability to host and monitor cells. The results showed that the solids content and formulation of the PEDOT/xanthan gum dispersion can be used to adjust the porosity and formation of layers. The samples presented interconnected pores with adjustable sizes between 10 and $150 \mu \mathrm{m}$, and adequacy of the mechanical properties, with Young modules between 10 and $45 \mathrm{kPa}$. The pore size and stiffness can be adjusted according to the target cell culture. These electrical conductive scaffolds can promote cell growth by electrical stimulation, which is advantageous for some cells, such as the cardiac, muscular, and neural, with the possibility of measuring their impedance to monitor cell growth as an additional tool [59]. The scaffolds developed in this work present an interesting cellular monitoring aspect through scaffold impedance measurements at different time intervals. 
The use of other polysaccharides or even mixtures of polysaccharides could be included in these scaffolds in future works.

The TIPS and freeze-drying are techniques are evolving in the field of development of polymeric scaffolds and show the evident application potential. They present perspectives of use in tissue engineering [46], such as complex tissue regeneration [50], development of compatible biological coatings [51], functional small-diameter vascular graft [52], large bone defect repair [58], and controlled delivery systems for drugs or other active materials [53]. In the future, some shortcomings still have to be overcome, such as the use of toxic solvents and the tissue shrinkage, usually observed after the drying step.

\subsection{Electrospinning}

Electrospinning is an effective technique used to produce micro and nanoscale fibers from polymers and composite materials [60]. A variety of polymer solutions and melts can be used to obtain polymeric fibers with diameters varying from $3 \mathrm{~nm}$ to $6 \mu \mathrm{m}$, and several meters in length [61]. The scaffolds fabricated with electrospinning fibers present large surface area, high porosity density, and controllable alignment, allowing the cell attachment and growth in preferred orientation [62]. Also, electrospinning scaffolds have a fibrous architecture similar to the native extracellular matrix (ECM) [13]. The combination of these remarkable properties expands the use of scaffolds obtained by electrospinning for tissue engineering as substrate material for cells to regenerate new ECM [63]. Some works have already shown their use as temporary support for tendon, bone, cartilage, trachea, meniscus, muscle, skeletal, and neural tissue $[60,63,64]$. Also, recent works in the literature have shown the use of electrospinning for the production of fibrous scaffolds for drug delivery systems and cancer therapy [65].

One of the main advantages of electrospinning is the setup simplicity, which consists of three parts, Figure 3a: a syringe pump with a metallic needle, a high-power voltage source, and a metallic collector $[66,67]$. In a conventional electrospinning process, a polymer solution is held at a needle tip by surface tension. The application of an electrical field using a high-power voltage source induces charges within the polymer, leading to charge repulsion within the solution. The initiation of a polymer jet happens when the electrical potential overcomes the surface tension. The jet travels rapidly to the collector, allowing the solvent to evaporate, and a continuous polymer fiber is collected [61, 67]. The final characteristic of the polymer fiber will depend on the solution properties (polymer concentration, polymer molecular weight, conductivity, surface tension, and volatility), the processing variables (flow rate, applied voltage, needle tip design, collector composition and geometry, and distance between the needle and the collector), and the ambient parameters (temperature, humidity, and air velocity) $[67,68]$. The disadvantages of electrospinning are the use of organic solvents and the small volumes of scaffolds obtained at low rates [61, 62, 64, 69].

The concentration of polymer in the solution is one of the most important variables in the electrospinning process since it will define the fiber size and morphology. Usually, increasing the polymer concentration results in fibers with higher diameters [70]. The incorporation of conductive nanoparticles in the polymeric solution can also interfere with the fiber diameter. Usually, the fibrous networks produced by the electrospinning technique can present both two-dimensional (2D) and three-dimensional (3D) macrostructures, with randomly oriented mats or aligned fibrous arrays and different shapes, as porous, core-shell, hollow, and honeycomb. The scaffolds' thickness increases with the spinning time, which can lead to a 3D structure with the thickness varying from 10 to $100 \mu \mathrm{m}$ [71]. The dimensions of 2D macrostructures are limited by the shape and size of the collector [72].

Several natural and synthetic polymers have been employed in the fabrication of scaffolds through electrospinning technique, such as collagen, gelatin, silk, CS, fibrinogen, polyvinylpyrrolidone (PVP), polymethyl methacrylate (PMMA), polyethylene oxide (PEO), nylon-6, cellulose acetate (CA), PVA, PLGA, PEG, PCL and PLA [13, 65, 73]. For each polymer, a proper solvent must be used, being the most common methanol, ethanol, DMF, THF, toluene, acetone, formic acid, CL, and water [73]. Polymers molten at a high temperature can also be used in the electrospinning process. In this case, instead of a solution, the polymer melt is introduced into the syringe pump [74]. Electrospinning presents many advantages when compared to other polymeric scaffold production techniques. As mentioned, this process is developed using a simple instrument that is very cost-effective. The production of polymeric fibers, in this case, is 
continuous and scalable, with the ability to fabricate fibers with different diameters. The process is very versatile and reproducible since the electrospinning instrument has several variables that are easily controllable [61, 69]. Also, the electrospinning technique allows the incorporation of several organic and inorganic nanoparticles into the polymers to improve antimicrobial activity, cellular proliferation, and to enhance the mechanical properties of the scaffolds [75]. Our research group has successfully produced PHBV electrospun mats reinforced with titanium dioxide $\left(\mathrm{TiO}_{2}\right)$ to be used as scaffolds for tissue regeneration [76]. $\mathrm{TiO}_{2}$ nanoparticles were synthesized by hydrothermal method, and the mats were prepared by adding $1.0,2.5$, and $5.0 \mathrm{wt} \%$ of $\mathrm{TiO}_{2}$ to the electrospinning solution. Interconnected, uniform, and homogeneous fibers, with cylindrical shapes were obtained for all compositions. Cell viability was evaluated using murine embryonic fibroblasts (MEF) through the colorimetric method of reduction of 3-(4,5-dimethylthiazol-2-yl)-2,5 diphenyl tetrazolium bromide (MTT). The addition of $\mathrm{TiO}_{2}$ nanoparticles increased cell viability after $24 \mathrm{~h}$ for all concentrations compared to PHBV; however, after $72 \mathrm{~h}$, there was a decrease in the viability for the sample with $5 \mathrm{wt} \% \mathrm{TiO}_{2}$, and after $96 \mathrm{~h}$, all nanocomposites presented viabilities lower than the obtained for pure PHBV mat. This behavior was explained because, after this incubation time, cells reached confluence in the well, and so occurred cell death and/or growth inhibition. The results exhibit great potential for using $\mathrm{PHBV} / \mathrm{TiO}_{2}$ mats for tissue regeneration; still, additional evaluations are necessary to explain the behavior of cell viability reduction after longer incubation times.

CS scaffolds were produced through electrospinning containing $0.3,0.6$, and $1.0 \mathrm{wt} \%$ of PEDOT/polystyrene sulfonate (PEDOT:PSS), a conductive polymer [77]. The objective was to improve the tensile strength, electrical properties, biocompatibility, and cell viability to use this scaffold for cardiac tissue regeneration. SEM images showed that the increase in PEDOT:PSS content resulted in a decrease in fiber diameter. This result was associated with the conductive properties of PEDOT:PSS filler, which increased the electrical conductivity of the polymeric solution during the electrospinning process and facilitated the pulling of the polymeric jet. The addition of $1 \mathrm{wt} \%$ of PEDOT:PSS in CS scaffolds reduced the fiber diameter by $30-40 \%$ and also increased the electrical conductivity by around 100fold. In addition, the tensile strength increased about $100 \%$ and the cell attachment was superior for the scaffolds with a reduction in fiber diameter when compared to the control, without any cell toxicity [77]. Although authors achieved the desired enhancement in the mechanical and electrical properties for the CS scaffolds, in vivo assays and cytotoxicity evaluation are necessary to continue the study for human applications.

Another study [78] fabricated a nanofiber scaffold consisting of cellulose with the incorporation of $\mathrm{TiO}_{2}$ $(1.0,1.5$, and $2.0 \mathrm{wt} \%)$ and silver nanoparticles (AgNPs) (3.0, 5.0, and $7.0 \mathrm{wt} \%$ ) through the electrospinning process. The objective was to produce a multifunctional scaffold for bone tissue regeneration, associating antibacterial and bioactivity properties. The antibacterial properties were investigated against Escherichia coli and Staphylococcus aureus by disc diffusion method, showing that scaffolds with the addition of 5.0 and $7.0 \mathrm{wt} \%$ of AgNPs presented higher inhibition potential. Pristine cellulose scaffold showed no inhibition zone, indicating no antibacterial activity. Regarding the cell viability, MTT assay was carried out after culturing of fibroblast. The results showed that by increasing the $\mathrm{TiO}_{2}$ concentration from 1.0 to $2.0 \mathrm{wt} \%$, the cell viability and proliferation also increased. According to the authors, the introduction of $\mathrm{TiO}_{2}$ and $\mathrm{AgNPs}$ in electrospun cellulose scaffolds improved the viability of fibroblasts and incorporated antibacterial attributes to the material [78]. However, a more detailed study is necessary to evaluate the proper amount of AgNPs to be inserted in the cellulose scaffolds since the addition of AgNPs in higher concentrations showed a toxic effect on the viability of the fibroblasts. Besides, in vitro assays regarding osteoblast differentiation would be interesting since the study is focused on bone tissue regeneration. Nevertheless, in vivo assays are also necessary for future studies.

Recently, many works have shown the use of the electrospinning process to produce hollow and coreshell nanofibers. The objective is to incorporate biologically active molecules into the polymeric fibers, prevent the decomposition of a biological agent or unstable compound, enhance the mechanical properties, deliver a biomolecular drug in a controlled way, and functionalize the surface of fiber without compromising the core material $[69,79]$. Ultrathin electrospun core-shell fibers based on PCL, PEG, 
gelatin, and osteogenic growth peptide (OGP) were prepared to evaluate the biological response and bacterial growth inhibition [80]. In this work, PCL was the core, and the combination of gelatin, PEG, and OGP was the shell. The developed core-shell scaffolds showed similar mechanical properties as those of neat PCL and superior mechanical properties when compared to non-core shell scaffolds with the same composition. The addition of OGP in the scaffold resulted in enhanced calcium deposition and alkaline phosphate activity compared to neat PCL, indicating osteoblast differentiation and upregulating the human osteoblast cells (hFOB). In addition, significantly improved antibacterial activity against $P$. aeruginosa was also observed for the developed material. The results showed a promising core-shell scaffold for application as bone tissue engineering material [80]. Nevertheless, further investigations regarding antibacterial resistance against others Gram-positive, Gram-negative, and multidrug-resistance bacteria would complement the study. In addition, biodegradation assays of the core-shell scaffolds are necessary to fully understand the antibacterial mechanism, the controlled release of OGP, and the efficacy of tissue regeneration.

The electrospinning technique also has some factors that limit its application in some fields. The main disadvantage regarding the electrospinning process is related to the use of organic solvents, which are usually toxic and present some risks to the environment and human health [62]. Several works have been studying the substitution of these organic solvents for others with fewer risks to overcome this problem [81, 82]. Besides, the production of great amounts of scaffolds is limited through this technique since the electrospinning process allows the production of small volumes of scaffolds at low rates [64].

Even with some disadvantages, the electrospinning technique is still one of the most developed and explored methods for the production of polymeric scaffolds for application in the biomedical field due to its simple apparatus. Further investigations regarding the production of 3D fibrous structures with defined thickness and accurate $3 \mathrm{D}$ design are necessary to expand the application of this technique. The control of some key parameters (as polymer solution concentration, viscosity, applied voltage, and ambient conditions) and the development of novel techniques (as multi-layering electrospinning and folding/accumulating 2D fiber films) are necessary to achieve this goal. The possibility of producing scaffolds with several shapes, as porous, core-shell, hollow, and honeycomb, in 2D and 3D configurations will expand their perspective of use in tissue engineering and also as therapeutic agent release [71].

\subsection{Thermally induced self agglomeration (TISA)}

Despite being one of the most studied techniques in the tissue engineering field, electrospinning is associated with a big limitation that is the production of $2 \mathrm{D}$, or $3 \mathrm{D}$ constructs with limited thickness, with small pores and lack of larger pores for cell penetration and tissue formation, because the mats are usually overlaid [83]. To overcome these drawbacks, Xu et al. [84] reported for the first time in 2015 an innovative approach consisting of thermally induced nanofiber self-agglomeration (TISA) followed by freeze-drying. TISA consists of several distinct steps, being the first one the production of fibrous membranes by electrospinning. The obtained mats are then cut into small pieces around $1 \mathrm{~cm}$ and then placed into a mortar containing liquid nitrogen to be broken into tiny pieces upon mechanical grinding. The ground material is then collected and dispersed in a mixture of solvents and gelatin aqueous solution to obtain a uniform dispersion and good control of agglomeration. After that, the suspension is heated to spontaneously agglomerate into 3D structures, to be posteriorly rinsed and freeze-dried [83-85]. Figure 3b shows the main steps to obtain 3D scaffolds via TISA. One of the disadvantages of TISA is that in some cases, to obtain the mats is necessary to use organic solvents; that represent risks to the environment and

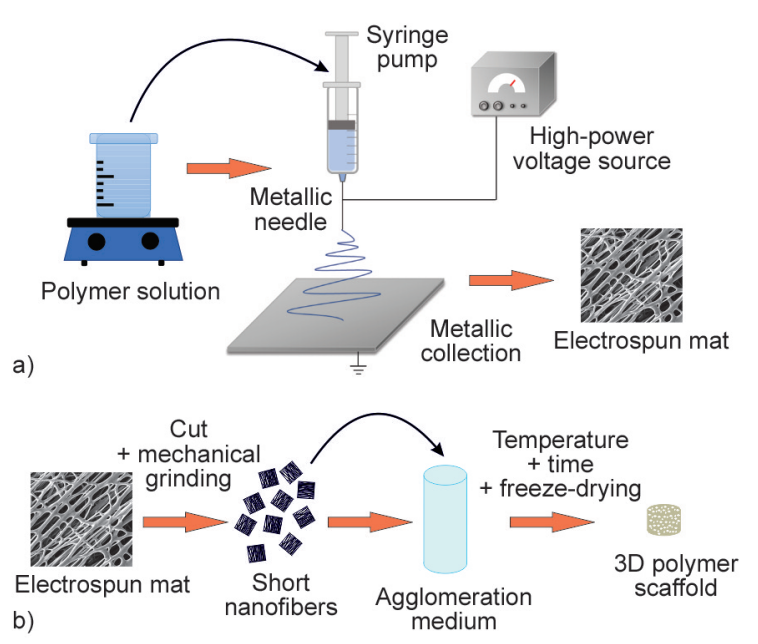

Figure 3. Simplified scheme of (a) electrospinning and (b) TISA. 
human health. Besides that, the technique requires several steps and allows producing small volumes of scaffolds at low rates. The greatest limitations are the mechanical properties, which do not allow these structures to be used in places of high mechanical stress. The dimensions of samples are limited by the lyophilization step, once freeze dryers usually have small flasks. Samples of about $1 \times 1 \times 1 \mathrm{~cm}^{3}$ have been reported in the literature [84], therefore this is a technique still being developed and evolving.

TISA methodology was employed to produce 3D nanofibrous PCL scaffolds functionalized with HA and BMP2 signaling activator phenamil, to achieve enhanced osteogenic differentiation [86]. Scaffolds were obtained from previously electrospun PCL mats with fibers diameters from $200 \mathrm{~nm}$ to $1 \mu \mathrm{m}$. After the electrospinning process, the mats were cut into tiny pieces, and the shortened fibers were placed into a flask containing water/gelatin/ethanol solution and submerged into a water bath at $55^{\circ} \mathrm{C}$ for $3 \mathrm{~min}$. After that, the flask with the agglomerate was placed into ice water, and finally, the obtained scaffold was washed several times to remove any residual gelatin and ethanol. The functionalization with HA was accomplished via immersion in SBF. The obtained scaffolds showed porous morphology, with interconnected pores and minimal pore obstruction after the functionalization with HA. Functionalized scaffolds showed improved osteogenic differentiation of $\mathrm{C} 2 \mathrm{C} 12$ cells with phenamil, with no impact on cell viability and growth. This result suggested that PCL scaffolds functionalized with HA and combined with phenamil are promising for BPM2-induced bone formation [86]. This study was complete regarding the characterization, as in vitro and in vivo assays. The average results are mean of 3 measurements, including for the biological assays. So, despite promising results, the tested groups were too small, being necessary to make a new evaluation with a higher number of samples. Besides that, the authors only evaluated the results through a two-tailed homoscedastic t-test. For the assays with more than 2 groups, it is necessary to perform ANOVA, considering non-normal distribution and unpaired samples.

In a different approach, PLGA/PCL-BMP2 3D scaffolds were produced via TISA for bone regeneration [87]. The electrospun scaffolds were prepared as a core-shell structure, where the shell was a blend of PLGA and PCL, and the core consisted of BMP-2 with bovine serum albumin. A coaxial electrospinning process was used to obtain the desired core-shell structure. Then, 3D scaffolds were prepared via the TISA technique. SEM characterization showed porous 3D scaffolds with interconnected pores resembling natural ECM, which are beneficial for cell growth and tissue regeneration. Scaffolds presented a sustained release of BMP-2 within all the time periods evaluated, along with improved rat adipose-derived stem cells (rADSCs) attachment, proliferation, and osteogenic differentiation. The authors concluded that 3D scaffolds with osteoinductive growth factors are potential candidates for reconstructing bone defects in bone tissue engineering and dental medicine applications [87]. Authors invested in a core-shell technology to produce the scaffolds; however, this is not obvious why, because the structures were used to obtain 3D scaffolds via TISA. The report was complete concerning in vitro studies; nevertheless, in vivo evaluation is still necessary. Besides performing statistical analysis and reporting the differences between groups, the authors did not mention the populational size $(n)$ for each characterization.

TISA technique was also studied to produce CA/PCL soft and elastic 3D scaffolds, with interconnected porous morphology similar to natural ECM [88]. CA/PCL scaffolds were hydrolyzed to convert CA into regenerate cellulose (RC). CA/PCL scaffolds had a hydrophobic character, with a contact angle of about $136.5^{\circ}$, an ideal absorbent for organic compounds as a spongy gel or drug delivery. The scaffolds became hydrophilic after the conversion of CA into $\mathrm{RC}$ and were mechanically robust under wet conditions, which are important characteristics for cell functions and tissue formation. The obtained scaffolds, according to the authors, showed to be promising for a variety of applications, especially related to tissue engineering [88]. This paper reported a very detailed methodology to obtain 3D scaffolds for tissue engineering via TISA and used CA as an example of polymer for biomedical application. The morphological characterization was performed; however, no mention of statistical analysis or populational size was made. In vitro and in vivo studies are necessary to confirm the potential to be used as tissue engineering scaffolds.

TISA is a recent technique with great potential to be used for tissue engineering. Meanwhile, some obstacles still remain, such as the low mechanical properties and the need to sometimes use environmentally unfriendly organic solvents in the electrospinning 
step. However, it is a promising technique, once it is cheap, versatile, and can be used with polymers soluble in green solvents. The microstructures obtained closely mimic the ECM, not only in terms of fiber diameter but also in terms of the interconnected porosity achieved.

\subsection{D printing}

The 3D printing technology is considered one of the most popular recent additive manufacturing processes that allow the fabrication of biostructures with desirable biological, structural, and mechanical properties. Combined with modern research in nanotechnology, cell biology, and material science, 3D printing is one of the most interesting options to improve tissue engineering design to support the restoration and reconstruction of damaged organs and tissues [89-91]. For this reason, 3D printing is used in the production of safe, stable, and cost-efficient implantable scaffolds [89], offering the advantage of fabricating complex geometries with homogenous distribution of cells [92].

The 3D printing process first came to light in 1986 by Charles W. Hull, who used the method called stereolithography (SLA) [91]. Following this event, in 1993, Langer and Vacanti introduced the idea of 'Tissue Engineering' to describe the transplantation of selective cells using a bioabsorbable artificial polymer matrix to restore tissue function [92]. In their study, it was used for culturing single cells and clusters of fetal and adult hepatocytes, small intestine, and pancreatic islet cells. These cells were seeded onto different biodegradable polymeric matrices for 4 days, followed by implantation in a host animal. Part of these implantations resulted in viable hepatocytes transplantation showing mitotic figures and vascularization of cell clusters. Consequently, combining $3 \mathrm{D}$ printing and tissue engineering concepts, it becomes possible to obtain parts called scaffolds that are artificial gadgets made of biomaterial intended to repair or replace injured tissues [93].

The 3D printing techniques can be classified into non-biological and biological methods. The non-biological method includes fused deposition modeling (FDM), SLA, selective laser sintering (SLS), selective laser (SLM), or electron beam melting (EBM). Depending on the printing material selected, these methods can be applied in some biological structures. On the other side, the completely biological method is called 3D bioprinting and it is divided into three categories: inkjet, laser-assisted, and extrusion [90].

The essential steps involved in 3D bioprinting consist of prebioprinting, bioprinting, and postbioprinting. The first step includes the selection of the biomaterial and the use of computer tomography (CT), magnetic resonance imaging (MRI), and X-ray to blueprint the desired organ shape. The 3D representation of the organ shape is sent to the second step, which is the printing of a prototype model. The last step implies the conditioning of the organ printed in a bioreactor to promote the proliferation and differentiation of cells [94]. Thus, the geometry and dimensions of 3D parts can be obtained in many sizes depending on the equipment capacity, which can be tailored according to the application. Until now, it is reported many examples of devices printed such as vascularized tissue with a cross-section of $100 \mu \mathrm{m}$, trileaflet heart valve with $26 \mathrm{~mm}$ diameter, and an ear-shaped framework around $600 \times 300 \mathrm{~mm}$ [95-97].

Taking this into account, the 3D bioprinting process categories (inkjet, laser-assisted, and extrusion) can be shortly described as follows and are briefly schematized in Figure 4. The inkjet technique is based on a conventional inkjet printing process. This technique makes use of thermal or piezoelectric mechanical pulses to generate small-sized droplets with resolutions around 50-75 $\mu \mathrm{m}$ [11]. The process is done
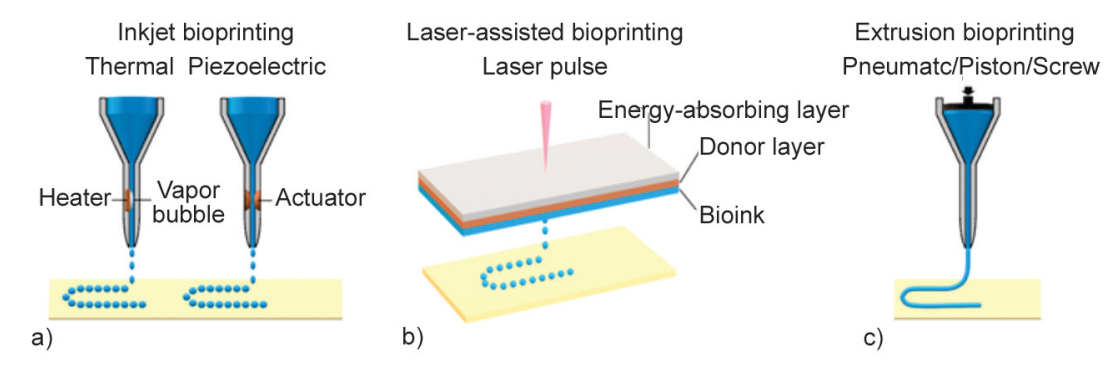

Figure 4. Simplified scheme for most common 3D bioprinting techniques: (a) inkjet bioprinting, (b) laser-assisted bioprinting, and (c) extrusion bioprinting [90]. 
in a continuous way to form patterns layer by layer generating a printed solid 3D final product. The advantages of 3D inkjet bioprinting are low cost, fast process, and wide accessibility. The main disadvantage is the nozzle clogging that can be avoided by a low viscosity bioink [90].

The laser-assisted technique consists of a focusing system, an absorbing layer called ribbon, and a substrate for the bioink layer. The laser pulses on the absorbing layer to create a high-pressure bubble on the bioink layer and then drop this bioink onto the substrate surface to obtain a printed part. This technique is capable of fabricating a high-precision shape [11]. The principal advantages of 3D laser-assisted bioprinting are the non-contact with the final product and elevated cell viability. The disadvantages of this technique are the complex operation of the equipment and time-consuming preparation [90].

The last but not least important is the extrusion method, which works with a constant mechanical force that uses pneumatic pressure to extrude a continuous line of bioink to print the desired product. The major advantage of $3 \mathrm{D}$ extrusion bioprinting is the high-density cell deposition, and the disadvantage comprises low cell viability. The materials used in the 3D bioprinters are called bioink and are mostly composed of polymer chains that can be from a natural or synthetic source [98]. Among the natural polymers most used for this purpose are alginate, gelatin, collagen, and hyaluronic acid. On the other hand, the most used synthetic polymers are PEG, PLGA, PCL, and PLLA. The main difference among them lies in the viscosity, where the natural polymers are more viscous due to their high molar weight [94].

Until now, the progress in 3D bioprinting has been vast and can be found in applications such as skin, heart valves, blood vessels, bone, cardiac tissue, and so forth [98]. Regarding this, a study on a 3D bioprinted retina model for retinal regeneration therapies was reported [99]. The retina piece was fabricated with the inkjet-based bioprinting strategy using a gelatin methacrylate (GelMa) polymer followed by a deposition layer-by-layer of matured photoreceptors cells (PRs), retinal pigment epithelium cells (RPE), and choroid cells. The analyses of the printed retina showed that the deposition of photoreceptor cells on the RPE monolayer did not alter cells' biological functions, such as morphology, viability, and expression of specific proteins. The results showed an engineered construct with considerable resemblance to the native retina. While no direct tests were conducted to assay outer segment phagocytosis and visual cycle activity, the protein expression data and microstructure imaging suggested that after bioprinting, both RPE and PRs could perform specific retinal functions [99]. Although this study did not present in vitro essays, it described a very detailed process of retina bioprinting aiming to overcome the regenerative medicine challenges associated with sightthreatening diseases, such as age-related macular degeneration and retinitis pigmentosa.

Another relevant aspect of $3 \mathrm{D}$ bioprinting is that this technology can fabricate tissues based on composite materials. Considering this, samples using a hydrogel based on alginate and GelMA reinforced with PCL fiber networks were printed, aiming to mimic the mechanical properties of articular cartilage [100]. The 3D printed constructs, called interpenetrating networks (IPN), were obtained by two types of printing technologies. The fibers were manufactured by FDM technology. Afterward, the samples obtained were placed in an extrusion printer to load the fibers with hydrogel bioink. The stress-relaxation test was used to determine the equilibrium modulus of the IPN in the absence of fluid flow. The result achieved for a double offset PCL + IPN configuration was $0,218 \mathrm{MPa}$. In parallel, the dynamic test was performed aiming to investigate the dynamic properties of a biomaterial, which reflect its capacity to generate fluid load support. In the case of articular cartilage, the dynamic property is associated with the low permeability of the solid matrix. The dynamic modulus found was $2.293 \mathrm{MPa}$. Both results meet partially the native articular cartilage (equilibrium modulus ranges from approximately 0.2 to $2 \mathrm{MPa}$, while the dynamic modulus ranges from approximately 10 to $60 \mathrm{MPa}$ ). The fact that the dynamic properties of the composite did not reach native values can be related to the significantly higher permeability than that of articular cartilage. Increasing the density of IPN (to increase the fluid load support), could lower the permeability to the detriment of cell nutrient transport and waste removal. Hence, the properties achieved can be viewed as a balance between providing initial mechanical function regarding the native equilibrium and an environment supportive of chondrogenesis associated with the dynamic properties. The results achieved in this work showed that the bioprinted biomimetic composites were found to support robust chondrogenesis, which is the process 
of cartilage development. In this way, it was concluded that $3 \mathrm{D}$ bioprinting can be used to engineer structures that are both biocompatible and biomimetic concerning the mechanical properties of articular cartilage [100]. Besides the mechanical tests, this study accomplished in vitro tests, which leaves the opportunity for further studies to analyze the in vivo performance of the material.

Beyond the application in tissue engineering, one of the most recent approaches of 3D bioprinting is on preclinical studies to comprehend the mechanisms of cancer occurrence. The laser-assisted 3D bioprinting (LAB) technique was used to generate 3D pancreatic cell spheroids arrays employing a hydrogel composed of GelMA [101]. The advantage presented by LAB in this study was the possibility to replicate a 3D scenario of the cancer cell evolution, permitting high control over cell number deposition and spatial resolution. The conventional studies of cancer cells are usually performed with $2 \mathrm{D}$ in vitro environmental models. However, this 2D method presents a lack of predictive value and is sometimes proven inconsistent with clinical trials results due to its low reproducibility, heterogeneity in spheroids size and distribution, and high variability of the extracellular matrix components. During the investigation, a marked increase of ductal cell proliferation in the 3D printed culture than in the $2 \mathrm{D}$ culture was observed. By this, the authors inferred that the fraction of the spheroids in the 3D bioprinted model was much more in line with the anticipated in vivo behavior of cells involved in the initial steps of pancreatic ductal adenocarcinoma (PDAC). This research made it possible to investigate more precisely the internal and external factors that contribute to the formation of PDAC lesions and cancer progression and conclude that $3 \mathrm{D}$ bioprinting demonstrates a new strategy to follow in PDAC therapy [101].

The image analysis and phenotypic characterization showed that $\mathrm{LAB}$ is a unique tool that permits high control over cell number deposition and spatial resolution. So, it was possible to investigate more precisely the internal and external factors that contribute to the formation of pancreatic ductal adenocarcino$\mathrm{ma}(\mathrm{PDAC})$ lesions and cancer progression. Therefore, by this study, the authors suggest that $3 \mathrm{D}$ bioprinting demonstrates to be a new strategy to follow in PDAC therapy, leaving the opportunity for new studies to carry on in vivo tests.
Advancements in 3D printing technology are getting more attractive in the biomedical field. Beyond the possibility of printing organs and tissues for partial or total replacement, this technology can be used in studies to understand the mechanisms of disease evolution, such as cancer. Some recent publications also point to 3D bioprinting as an alternative option to develop drugs and cosmetics to avoid the use of animals testing [102]. Another study also demonstrated the feasibility of an in situ skin bioprinting that aimed to repair a wounded surface [103]. Being a technology that offers many possibilities, it also presents many points of improvement for the future. Considering that the tissue organs are made of a complex organizational structure with different sizes, different rigidities, and different cells, it is necessary to develop equipment that can reproduce this configuration. The current devices do not have the capacity to combine multi-scale, multi-material, and multicell bioprinting. So, they are not able to reach precisely the delicate structure of natural tissues. In addition, the development and application of bioinks play an important role in bioprinting. Because of this, it is fundamental the constant improvement of bioink synthesis aiming to balance three main properties of printability, biocompatibility, and mechanical properties. Besides the challenges mentioned to be overcome, it is suggested the standardization of the in vitro tissue models to establish parameters of size, biological and mechanical properties [104]. Hence, many opportunities can be explored in the $3 \mathrm{D}$ printing world.

Table 1 summarizes all the aforementioned techniques, highlighting the main advantages and disadvantages of each of them.

\section{Conclusions and future perspectives}

Nowadays several methods are accessible for the tissue engineering field, with an enormous number of available polymers, which can be modified, functionalized, or used as composites to modulate their properties and fulfill the desired requirements. Each technique has its peculiarities and can be chosen for specific applications. In this review, the most recently cited methods used to produce porous polymer scaffolds, as well as their properties and applications, were shown. Owing to the remarkable properties and possibility of modifications, polymer scaffolds have attracted significant interest in the tissue engineering 
Table 1. Main advantages and disadvantages for the scaffolds production techniques.

\begin{tabular}{|c|c|c|c|}
\hline Technique & Advantages & Disadvantages & References \\
\hline Salt leaching & $\begin{array}{l}\text { - Control of the pore size } \\
\text { - Control of porosity } \\
\text { - Easy technique } \\
\text { - Good reproducibility }\end{array}$ & $\begin{array}{l}\text { Degradation through hydrolysis as soon } \\
\text { as the material is exposed to water } \\
\text { - Impossible to guarantee the complete re- } \\
\text { moval of salt }\end{array}$ & {$[4,5]$} \\
\hline Solvent casting & $\begin{array}{l}\text { - Simple and low-cost technique } \\
\text { - Samples can be quickly prepared } \\
\text { - High repeatability in film thickness } \\
\text { - Easy variation in reaction conditions }\end{array}$ & $\begin{array}{l}\text { - Possibility for retention of toxic solvent } \\
\text { within the scaffold }\end{array}$ & {$[26,28,34,105]$} \\
\hline Gas foaming & $\begin{array}{l}\text { Organic Solvent-free (eco-friendly) } \\
\text { Non-toxic, simple, reduced costs } \\
\text { Allows control of porosity, pore size, } \\
\text { and pore interconnectivity }\end{array}$ & $\begin{array}{l}\text { - Limitation of precursor polymer (crys- } \\
\text { talline polymers do not form foam) } \\
\text { - Necessity of having } T_{\mathrm{g}} \text { and } T_{\mathrm{m}} \text { compati- } \\
\text { ble with parameters of the gas used in } \\
\text { the process }\end{array}$ & {$[2,3,40-42]$} \\
\hline TIPS & $\begin{array}{l}\text { - Allows different pore morphologies and } \\
\text { sizes } \\
\text { Production in large scale and few pro- } \\
\text { cessing steps } \\
\text { - High interconnectivity of the porous net- } \\
\text { work } \\
\text { - Capability of integrating bioactive mole- } \\
\text { cules }\end{array}$ & $\begin{array}{l}\text { - Use of organic solvents- serious risk to } \\
\text { the environment and human health } \\
\text { High-energy consumption to obtain the } \\
\text { samples }\end{array}$ & [47-51] \\
\hline Freeze-drying & $\begin{array}{l}\text { - Use of biological samples without de- } \\
\text { naturation Allows the use of several } \\
\text { different solvents } \\
\text { - Channel-like pores and anisotropic } \\
\text { structure } \\
\text { - Tunable pore size and structure }\end{array}$ & $\begin{array}{l}\text { - Restrict to a small group of polymers } \\
\text { - Production in laboratory scale } \\
\text { - Time-consuming production } \\
\text { - Economically uncompetitive } \\
\text { - Use of cytotoxic organic solvents } \\
\text { - Typical tissue shrinkage }\end{array}$ & {$[46,51,53-55]$} \\
\hline Electrospinning & $\begin{array}{l}\text { - High control over the scaffolds' parame- } \\
\text { ters } \\
\text { - Cost effective } \\
\text { - Simple and versatile instrument } \\
\text { - Continuous and scalable process }\end{array}$ & $\begin{array}{l}\text { - Use of organic solvents in most cases - } \\
\text { serious risk to the environment and } \\
\text { human health } \\
\text { - Production of small volumes of scaf- } \\
\text { folds at low rates }\end{array}$ & {$[61,62,64,69]$} \\
\hline TISA & $\begin{array}{l}\text { - Morphology similar to ECM } \\
\text { - Can be used with different materials } \\
\text { - Simple and versatile experimental appa- } \\
\text { ratus } \\
\text { - Cheap technique }\end{array}$ & $\begin{array}{l}\text { - Use of organic solvents- serious risk to } \\
\text { the environment and human health } \\
\text { - Production of small volumes of scaf- } \\
\text { folds at low rates } \\
\text { - Low mechanical properties }\end{array}$ & [85-88] \\
\hline 3D Printing - Inkjet & $\begin{array}{l}\text { - Wide availability } \\
\text { - Fast fabrication speed } \\
\text { - Low cost } \\
\text { - High printing resolution } \\
\text { - Easy process }\end{array}$ & $\begin{array}{l}\text { - Nozzle clogging } \\
\text { - Only non-viscous bioink } \\
\text { - Low cell density }\end{array}$ & {$[91,106]$} \\
\hline 3D Printing - Laser assisted & $\begin{array}{l}\text { - Non-contact with the final product } \\
\text { - Wide range of bioink viscosity } \\
\text { - High cell viability } \\
\text { - High resolution } \\
\text { - Can operate with a wide range of vis- } \\
\text { cosities }\end{array}$ & $\begin{array}{l}\text { - Complex operation } \\
\text { - Time-consuming preparation } \\
\text { - High cost } \\
\text { - Low cell density }\end{array}$ & [91] \\
\hline 3D Printing - Extrusion & $\begin{array}{l}\text { - High cell density } \\
\text { - Can operate with high viscous bioink }\end{array}$ & $\begin{array}{l}\text { - Only viscous bioink } \\
\text { - Low cellular viability } \\
\text { - Slow fabrication speed } \\
\text { - Moderate printing resolution }\end{array}$ & {$[91,106]$} \\
\hline
\end{tabular}

field. Some polymers can be processed by several methodologies, while others have their application more restricted. Learning how to tailor porosity and mechanical properties is a key factor for the effective use of polymer scaffolds in tissue regeneration. Obtaining a scaffold with enough macro and microporosity so that the fluids and cells can reach the entire sample is essential to cell proliferation. Adjusting the techniques mentioned in this review and developing new ones to overcome some limitations such as mechanical resistance and samples sizes is extremely important. in vivo studies still need to be carried out. Obtaining innovative properties through modifications such as surface grafting, functionalization, surface 
coating, incorporation of nanoparticles, among others, is a future direction as valuable as the improvement of scaffold production techniques. Reducing or eliminating the use of toxic solvents must also be considered for future developments. The scientific community should concern about the data correct treatment and experimental planning. However, whatever it is the polymer or the application, further studies need to be carried out. Tailoring the materials' properties to obtain desired features and mimic natural tissues is a great challenge to be overcome.

\section{Acknowledgements}

This study was funded by the Brazilian Funding institutions FAPESP (Fundação de Amparo à Pesquisa do Estado de São Paulo) (2020/12507-6, 2017/24873-4, 2017/27079-7, 2017/ 02846-5; 2018/12035-7), FINEP (01.13.0328.03) and CAPES (Coordenação de Aperfeiçoamento de Pessoal de Nível Superior).

MHFernandes research is developed within the scope of the project CICECO-Aveiro Institute of Materials, UIDB/50011/ 2020 \& UIDP/50011/2020, financed by national Portuguese funds through the FCT/MEC and when appropriate co-financed by FEDER under the PT2020 Partnership Agreement.

\section{References}

[1] Jazayeri H. E., Lee S-M., Kuhn L., Fahimipour F., Tahriri M., Tayebi L.: Polymeric scaffolds for dental pulp tissue engineering: A review. Dental Materials, 36, e47-e58 (2020). https://doi.org/10.1016/j.dental.2019.11.005

[2] Ju J., Peng X., Huang K., Li L., Liu X., Chitrakar C., Chang L., Gu Z., Kuang T.: High-performance porous PLLA-based scaffolds for bone tissue engineering: Preparation, characterization, and in vitro and in vivo evaluation. Polymer, 180, 121707 (2019). https://doi.org/10.1016/j.polymer.2019.121707

[3] Manavitehrani I., Le T. Y. L., Daly S., Wang Y., Maitz P. K., Schindeler A., Dehghani F.: Formation of porous biodegradable scaffolds based on poly(propylene carbonate) using gas foaming technology. Materials Science and Engineering C, 96, 824-830 (2019).

https://doi.org/10.1016/j.msec.2018.11.088

[4] Jakus A. E., Geisendorfer N. R., Lewis P. L., Shah R. N.: 3D-printing porosity: A new approach to creating elevated porosity materials and structures. Acta Biomaterialia, 72, 94-109 (2018).

https://doi.org/10.1016/j.actbio.2018.03.039

[5] Refifi J., Oudadesse H., Merdrignac-Conanec O., El Feki H., Lefeuvre B.: Salt leaching using powder (SLUP) process for glass/chitosan scaffold elaboration for biomaterial applications. Journal of the Australian Ceramic Society, 56, 1167-1178 (2020).

https://doi.org/10.1007/s41779-020-00460-6
[6] do Amaral Montanheiro T. L., Montagna L. S., Patrulea V., Jordan O., Borchard G., Lobato G. M. M., Catalani L. H., Lemes A. P.: Evaluation of cellulose nanocrystal addition on morphology, compression modulus and cytotoxicity of poly(3-hydroxybutyrate-co-3-hydroxyvalerate) scaffolds. Journal of Materials Science, 54, 7198-7210 (2019).

https://doi.org/10.1007/s10853-019-03398-8

[7] Sankar D., Chennazhi K. P., Nair S. V., Jayakumar R.: Fabrication of chitin/poly(3-hydroxybutyrate-co-3-hydroxyvalerate) hydrogel scaffold. Carbohydrate Polymers, 90, 725-729 (2012).

https://doi.org/10.1016/j.carbpol.2012.05.041

[8] Sharmila G., Muthukumaran C., Kirthika S., Keerthana S., Kumar N. M., Jeyanthi J.: Fabrication and characterization of Spinacia oleracea extract incorporated alginate/carboxymethyl cellulose microporous scaffold for bone tissue engineering. International Journal of Biological Macromolecules, 156, 430-437 (2020). https://doi.org/10.1016/j.ijbiomac.2020.04.059

[9] do Amaral Montanheiro T. L., Montagna L. S., Patrulea V., Jordan O., Borchard G., Ribas R. G., Campos T. M. B., Thim G. P., Lemes A. P.: Enhanced water uptake of PHBV scaffolds with functionalized cellulose nanocrystals. Polymer Testing, 79, 106079 (2019).

https://doi.org/10.1016/j.polymertesting.2019.106079

[10] Radhakrishnan S., Nagarajan S., Belaid H., Farha C., Iatsunskyi I., Coy E., Soussan L., Huon V., Bares J., Belkacemi K., Teyssier C., Balme S., Miele P., Cornu D., Kalkura N., Cavaillès V., Bechelany M.: Fabrication of 3D printed antimicrobial polycaprolactone scaffolds for tissue engineering applications. Materials Science and Engineering: C, 118, 111525 (2021). https://doi.org/10.1016/j.msec.2020.111525

[11] Jeong H-J., Nam H., Jang J., Lee S-J.: 3D bioprinting strategies for the regeneration of functional tubular tissues and organs. Bioengineering, 7, 32 (2020). https://doi.org/10.3390/bioengineering7020032

[12] Zhang F., King M. W.: Biodegradable polymers as the pivotal player in the design of tissue engineering scaffolds. Advanced Healthcare Materials, 9, 1901358 (2020). https://doi.org/10.1002/adhm.201901358

[13] Kai D., Liow S. S., Loh X. J.: Biodegradable polymers for electrospinning: Towards biomedical applications. Materials Science and Engineering: C, 45, 659-670 (2014). https://doi.org/10.1016/j.msec.2014.04.051

[14] Deb P., Barua E., Deoghare A. B., das Lala S.: Development of bone scaffold using Puntius conchonius fish scale derived hydroxyapatite: Physico-mechanical and bioactivity evaluations. Ceramics International, 45, 10004-10012 (2019). https://doi.org/10.1016/j.ceramint.2019.02.044

[15] Deb P., Deoghare A. B., Borah A., Barua E., das Lala S.: Scaffold development using biomaterials: A review. Materials Today: Proceedings, 5, 12909-12919 (2018). https://doi.org/10.1016/j.matpr.2018.02.276 
[16] Barua E., Deoghare A. B., Chatterjee S., Sapkal P.: Effect of $\mathrm{ZnO}$ reinforcement on the compressive properties, in vitro bioactivity, biodegradability and cytocompatibility of bone scaffold developed from bovine bonederived HAp and PMMA. Ceramics International, 45, 20331-20345 (2019).

https://doi.org/10.1016/j.ceramint.2019.07.006

[17] Bejarano J., Boccaccini A. R., Covarrubias C., Palza $\mathrm{H}$.: Effect of $\mathrm{Cu}$ - and $\mathrm{Zn}$-doped bioactive glasses on the in vitro bioactivity, mechanical and degradation behavior of biodegradable PDLLA scaffolds. Materials, 13, 2908 (2020). https://doi.org/10.3390/ma13132908

[18] Yang S., Leong K-F., Du Z., Chua C-K.: The design of scaffolds for use in tissue engineering. Part I. Traditional Factors. Tissue Engineering, 7, 679-689 (2001). https://doi.org/10.1089/107632701753337645

[19] Volkov A. V., Muraev A. A., Zharkova I. I., Voinova V. V., Akoulina E. A., Zhuikov V. A., Khaydapova D. D., Chesnokova D. V., Menshikh K. A., Dudun A. A., Makhina T. K., Bonartseva G. A., Asfarov T. F., Stamboliev I. A., Gazhva Y. V., Ryabova V. M., Zlatev L. H., Ivanov S. Y., Shaitan K. V., Bonartsev A. P.: Poly (3-hydroxybutyrate)/hydroxyapatite/alginate scaffolds seeded with mesenchymal stem cells enhance the regeneration of critical-sized bone defect. Materials Science and Engineering C, 114, 110991 (2020).

https://doi.org/10.1016/j.msec.2020.110991

[20] Wibowo U. A., Judawisastra H., Barlian A., Alfarafisa N. M., Moegni K. F., Remelia M.: Development of salt leached silk fibroin scaffold using direct dissolution techniques for cartilage tissue engineering. International Journal on Advanced Science, Engineering and Information Technology, 9, 810-815 (2019).

https://doi.org/10.18517/ijaseit.9.3.4511

[21] Bejarano J., Detsch R., Boccaccini A. R., Palza H.: PDLLA scaffolds with $\mathrm{Cu}$ - and $\mathrm{Zn}$-doped bioactive glasses having multifunctional properties for bone regeneration. Journal of Biomedical Materials Research Part A, 7, 746-756 (2017).

https://doi.org/10.1002/jbm.a.35952

[22] Bédouin Y., Pellen Mussi P., Tricot-Doleux S., Chauvel-Lebret D., Auroy P., Ravalec X., Oudadesse H., Pérez F.: 3D cell culture to determine in vitro biocompatibility of bioactive glass in association with chitosan. Bio-Medical Materials and Engineering, 26, 169-181 (2015).

https://doi.org/10.3233/BME-151555

[23] Oudadesse H., Wers E., Bui X. V., Roiland C., Bureau B., Akhiyat I., Mostafa A., Chaair H., Benhayoune H., Fauré J., Pellen-Mussi P.: Chitosan effects on glass matrices evaluated by biomaterial. MAS-NMR and biological investigations. Korean Journal of Chemical Engineering, 30, 1775-1783 (2013).

https://doi.org/10.1007/s11814-013-0104-x
[24] Wers E., Oudadesse H., Lefeuvre B., MerdrignacConanec O., Barroug A.: Evaluation of the kinetic and relaxation time of gentamicin sulfate released from hybrid biomaterial bioglass-chitosan scaffolds. Applied Surface Science, 353, 200-208 (2015).

https://doi.org/10.1016/j.apsusc.2015.06.146

[25] Agostinacchio F., Mu X., Dirè S., Motta A., Kaplan D. L.: In situ 3D printing: Opportunities with silk inks. Trends in Biotechnology, 39, 719-730 (2021). https://doi.org/10.1016/j.tibtech.2020.11.003

[26] Safaei F., Khalili S., Khorasani S. N., GhasemiMobarakeh L., Neisiany R. E.: Porogen effect of solvents on pore size distribution of solvent-casted polycaprolactone thin films. Journal of Polymer Science and Engineering, 1, 1076 (2018).

https://doi.org/10.24294/jpse.v1i4.1076

[27] Ismail N. A., Mat Amin K. A., Razali M. H.: Novel gellan gum incorporated $\mathrm{TiO}_{2}$ nanotubes film for skin tissue engineering. Materials Letters, 228, 116-120 (2018).

https://doi.org/10.1016/j.matlet.2018.05.140

[28] Asadpour S., Yeganeh H., Ai J., Kargozar S., Rashtbar M., Seifalian A., Ghanbari H.: Polyurethane-polycaprolactone blend patches: Scaffold characterization and cardiomyoblast adhesion, proliferation, and function. ACS Biomaterials Science and Engineering, 4, 4299-4310 (2018). https://doi.org/10.1021/acsbiomaterials.8b00848

[29] da Silva A. P., do Amaral Montanheiro T. L., Montagna L. S., Andrade P. F., Durán N., Lemes A. P.: Effect of carbon nanotubes on the biodegradability of poly(3hydroxybutyrate-co-3-hydroxyvalerate) nanocomposites. Journal of Applied Polymer Science, 2019, 48020 (2019). https://doi.org/10.1002/app.48020

[30] Montagna L. S., do Amaral Montanheiro T. L., Borges A. C., Koga-Ito C. Y., Lemes A. P., Rezende M. C.: Biodegradation of PHBV/GNS nanocomposites by Penicillium funiculosum. Journal of Applied Polymer Science, 134, 44234 (2016).

https://doi.org/10.1002/app.44234

[31] do Amaral Montanheiro T. L., Cristóvan F. H., Machado J. P. B., Tada D. B., Durán N., Lemes A. P.: Effect of MWCNT functionalization on thermal and electrical properties of PHBV/MWCNT nanocomposites. Journal of Materials Research, 30, 55-65 (2014). https://doi.org/10.1557/jmr.2014.303

[32] Ragunathan S., Govindasamy G., Raghul D. R., Karuppaswamy M., VijayachandraTogo R. K.: Hydroxyapatite reinforced natural polymer scaffold for bone tissue regeneration. Materials Today: Proceedings, 23, 111-118 (2020) https://doi.org/10.1016/j.matpr.2019.07.712

[33] Zhu N., Che X.: Biofabrication of tissue scaffolds. in 'Advances in biomaterials science and biomedical applications' (ed.: Pignatello R.) InTechOpen, Rijeka, 315-328 (2013). 
[34] Cesur S., Küçükgöksel Y., Taşdemir Ş., Ürkmez A. Ş.: Polycaprolactone-hydroxy apatite composites for tissue engineering applications. Journal of Vinyl and Additive Technology, 24, 248-261 (2018).

https://doi.org/10.1002/vnl.21569

[35] de Menezes B. R. C., do Amaral Montanheiro T. L., da Graça Sampaio A.., Koga-Ito C. Y., Thim G. P., Montagna L. S.: PCL $/ \beta-\mathrm{AgVO}_{3}$ nanocomposites obtained by solvent casting as potential antimicrobial biomaterials. Journal of Applied Polymer Sciences, 138, 50130 (2020).

https://doi.org/10.1002/app.50130

[36] Toong D. W. Y., Toh H. W., Ng J. C. K., Wong P. E. H., Leo H. L., Venkatraman S., Tan L. P., Ang H. Y., Huang Y.: Bioresorbable polymeric scaffold in cardiovascular applications. International Journal of Molecular Sciences, 21, 3444 (2020).

https://doi.org/10.3390/ijms21103444

[37] Salerno A., Oliviero M., Di Maio E., Iannace S., Netti P. A.: Design of porous polymeric scaffolds by gas foaming of heterogeneous blends. Journal of Materials Science: Materials in Medicine, 20, 2043-2051 (2009). https://oi.org/10.1007/s10856-009-3767-4

[38] Ursu A. V., Furtuna D., Requia L., Larafa S., de Baynast H., Michaud P., Djelveh G., Delattre C.: Comparison study between batch and continuous processes to obtain chitosan-based high porous biomaterial for biological applications. International Journal of Polymer Science, 2019, 2603757 (2019).

https://doi.org/10.1155/2019/2603757

[39] Laurencin C. T., Nair L. S.: Nanotechnology and tissue engineering: The scaffold. CRC Press, Boca Raton (2008). https://doi.org/10.1201/9781420051834

[40] Liu P., Chen W., Liu C., Tian M., Liu P.: A novel poly(vinyl alcohol)/poly(ethylene glycol) scaffold for tissue engineering with a unique bimodal open-celled structure fabricated using supercritical fluid foaming. Scientific Reports, 9, 9534 (2019).

https://doi.org/10.1038/s41598-019-46061-7

[41] Wang L., Wang D., Zhou Y., Zhang Y., Li Q., Shen C.: Fabrication of open-porous PCL/PLA tissue engineering scaffolds and the relationship of foaming process, morphology, and mechanical behavior. Polymers for Advanced Technologies, 30, 2539-2548 (2019). https://doi.org/10.1002/pat.4701

[42] Ju J., Gu Z., Liu X., Zhang S., Peng X., Kuang T.: Fabrication of bimodal open-porous poly(butylene succinate)/cellulose nanocrystals composite scaffolds for tissue engineering application. International Journal of Biological Macromolecules, 147, 1164-1173 (2020). https://doi.org/10.1016/j.ijbiomac.2019.10.085

[43] Costantini M., Barbetta A.: Gas foaming technologies for 3D scaffold engineering. in 'Functional 3D tissue engineering scaffolds' (eds.: Deng Y., Kuiper J.) Woodhead, Sawston, 127-149 (2018). https://doi.org/10.1016/B978-0-08-100979-6.00006-9
[44] Fried J. R.: Polymer science and technology. Prentice Hall, Westford (2014).

[45] van der Heijden P.: A DSC-study on the demixing of binary polymer solutions. PrintPartners Ipskamp, Enschede (2001)

[46] Ho M-H., Kuo P-Y., Hsieh H-J., Hsien T-Y., Hou L-T., Lai J-Y., Wang D-M.: Preparation of porous scaffolds by using freeze-extraction and freeze-gelation methods. Biomaterials, 25, 129-138 (2004). https://doi.org/10.1016/S0142-9612(03)00483-6

[47] Ruiz I., Hermida É. B., Baldessari A.: Fabrication and characterization of porous PHBV scaffolds for tissue engineering. Journal of Physics: Conference Series, 332, 012028 (2011). https://doi.org/10.1088/1742-6596/332/1/012028

[48] Hutmacher D., Schantz T., Zein I., Ng K. W., Teoh S., Tan K.: Mechanical properties and cell cultural response of polycaprolactone scaffolds designed and fabricated via fused deposition modeling. Journal of Biomedial Materials Research, 55, 203-216 (2001).

https://doi.org/10.1002/1097-4636(200105)55:2<203::AIDJBM1007>3.0.CO;2-7

[49] Zhijiang C., Yi X., Haizheng Y., Jia J., Liu Y.: Poly(hydroxybutyrate)/cellulose acetate blend nanofiber scaffolds: Preparation, characterization and cytocompatibility. Materials Science and Engineering: C, 58, 757767 (2016). https://doi.org/10.1016/j.msec.2015.09.048

[50] Ke Y., Wu G., Wang Y.: PHBV/PAM scaffolds with local oriented structure through UV polymerization for tissue engineering. BioMed Research International, 2014, 157987 (2014) https://doi.org/10.1155/2014/157987

[51] Cao Y., Mitchell G., Messina A., Price L., Thompson E., Penington A., Morrison W., O'Connor A., Stevens G., Cooper-White J.: The influence of architecture on degradation and tissue ingrowth into three-dimensional poly(lactic-co-glycolic acid) scaffolds in vitro and in vivo. Biomaterials, 27, 2854-2864 (2006).

https://doi.org/10.1016/j.biomaterials.2005.12.015

[52] Wang W., Liu D., Li D., Du H., Zhang J., You Z., Li M., He C.: Nanofibrous vascular scaffold prepared from miscible polymer blend with heparin/stromal cell-derived factor-1 alpha for enhancing anticoagulation and endothelialization. Colloids and Surfaces B: Biointerfaces, 181, 963-972 (2019). https://doi.org/10.1016/j.colsurfb.2019.06.065

[53] Maia J. L., Santana M. H. A., Ré M. I.: The effect of some processing conditions on the characteristics of biodegradable microspheres obtained by an emulsion solvent evaporation process. Brazilian Journal of Chemical Engineering, 21, 1-12 (2004). https://doi.org/10.1590/S0104-66322004000100002 
[54] Harris L. D., Kim B-S., Mooney D. J.: Open pore biodegradable matrices formed with gas foaming. Journal of Biomedical Materials Research, 42, 396-402 (1998).

https://doi.org/10.1002/(sici)10974636(19981205)42:3<396::aid-jbm7>3.0.co;2-e

[55] Perez-Puyana V., Jiménez-Rosado M., Romero A., Guerrero A.: Polymer-based scaffolds for soft-tissue engineering. Polymers, 12, 1566 (2020). https://doi.org/10.3390/polym12071566

[56] Sultana N., Wang M.: PHBV tissue engineering scaffolds fabricated via emulsion freezing/freeze-drying: Effects of processing parameters. in 'International Conference on Biomedical Engineering and Technology 2011. Singapore' Vol. 11, 29-34 (2011).

[57] Ke Y., Wang Y. J., Ren L., Zhao Q. C., Huang W.: Modified PHBV scaffolds by in situ UV polymerization: Structural characteristic, mechanical properties and bone mesenchymal stem cell compatibility. Acta Biomaterialia, 6, 1329-1336 (2010). https://doi.org/10.1016/j.actbio.2009.10.026

[58] Yao Q., Liu Y., Pan Y., Miszuk J. M., Sun H.: One-pot porogen free method fabricated porous microsphereaggregated 3D PCL scaffolds for bone tissue engineering. Journal of Biomedical Materials Research Part B: Applied Biomaterials, 108, 2699-2710 (2020). https://doi.org/10.1002/jbm.b.34601

[59] del Agua I., Marina S., Pitsalidis C., Mantione D., Ferro M., Iandolo D., Sanchez-Sanchez A., Malliaras G. G., Owens R. M., Mecerreyes D.: Conducting polymer scaffolds based on poly(3,4-ethylenedioxythiophene) and xanthan gum for live-cell monitoring. ACS Omega, 3, 7424-7431 (2018). https://doi.org/10.1021/acsomega.8b00458

[60] Cheng A., Schwartz Z., Kahn A., Li X., Shao Z., Sun M., Ao Y., Boyan B. D., Chen H.: Advances in porous scaffold design for bone and cartilage tissue engineering and regeneration. Tissue Engineering Part B: Reviews, 25, 14-29 (2019).

https://doi.org/10.1089/ten.teb.2018.0119

[61] Kumbar S. G., James R., Nukavarapu S. P., Laurencin C. T.: Electrospun nanofiber scaffolds: Engineering soft tissues. Biomedical Materials, 3, 34002 (2008). https://doi.org/10.1088/1748-6041/3/3/034002

[62] Sadeghi A., Moztarzadeh F., Mohandesi J. A.: Investigating the effect of chitosan on hydrophilicity and bioactivity of conductive electrospun composite scaffold for neural tissue engineering. International Journal of Biological Macromolecules, 121, 625-632 (2019). https://doi.org/10.1016/j.ijbiomac.2018.10.022

[63] Kang Y., Wang C., Qiao Y., Gu J., Zhang H., Peijs T., Kong J., Zhang G., Shi X.: Tissue-engineered trachea consisting of electrospun patterned sc-PLA/GO- $g$-IL fibrous membranes with antibacterial property and 3Dprinted skeletons with elasticity. Biomacromolecules, 20, 1765-1776 (2019).

https://doi.org/10.1021/acs.biomac.9b00160
[64] Jenkins T. L., Little D.: Synthetic scaffolds for musculoskeletal tissue engineering: Cellular responses to fiber parameters. npj Regenerative Medicine, 4, 15 (2019). https://doi.org/10.1038/s41536-019-0076-5

[65] Contreras-Cáceres R., Cabeza L., Perazzoli G., Díaz A., López-Romero J. M., Melguizo C., Prados J.: Electrospun nanofibers: Recent applications in drug delivery and cancer therapy. Nanomaterials, 9, 656 (2019). https://doi.org/10.3390/nano9040656

[66] Ambekar R. S., Kandasubramanian B.: Progress in the advancement of porous biopolymer scaffold: Tissue engineering application. Industrial and Engineering Chemistry Research, 58, 6163-6194 (2019). https://doi.org/10.1021/acs.iecr.8b05334

[67] Pham Q. P., Sharma U., Mikos A. G.: Electrospinning of polymeric nanofibers for tissue engineering applications: A review. Tissue engineering, 12, 1197-1211 (2006).

https://doi.org/10.1089/ten.2006.12.1197

[68] Nemati S., Kim S-J., Shin Y. M., Shin H.: Current progress in application of polymeric nanofibers to tissue engineering. Nano convergence, 6, 36 (2019). https://doi.org/10.1186/s40580-019-0209-y

[69] Zahedi E., Esmaeili A., Eslahi N., Shokrgozar M. A., Simchi A.: Fabrication and characterization of coreshell electrospun fibrous mats containing medicinal herbs for wound healing and skin tissue engineering. Marine drugs, 17, 27 (2019). https://doi.org/10.3390/md17010027

[70] Angel N., Guo L., Yan F., Wang H., Kong L.: Effect of processing parameters on the electrospinning of cellulose acetate studied by response surface methodology. Journal of Agriculture and Food Research, 2, 100015 (2020).

https://doi.org/10.1016/j.jafr.2019.100015

[71] Rahmati M., Mills D. K., Urbanska A. M., Saeb M. R., Venugopal J. R., Ramakrishna S., Mozafari M.: Electrospinning for tissue engineering applications. Progress in Materials Science, 117, 100721 (2021). https://doi.org/10.1016/j.pmatsci.2020.100721

[72] Ramakrishna S., Fujihara K., Teo W-E., Lim T-C., Ma $\mathrm{Z}$.: An introduction to electrospinning and nanofibers. World Scientific, Singapore (2005).

[73] Ewaldz E., Brettmann B.: Molecular interactions in electrospinning: From polymer mixtures to supramolecular assemblies. ACS Applied Polymer Materials, 1, 298-308 (2019). https://doi.org/10.1021/acsapm.8b00073

[74] Huang Z-M., Zhang Y-Z., Kotaki M., Ramakrishna S.: A review on polymer nanofibers by electrospinning and their applications in nanocomposites. Composites Science and Technology, 63, 2223-2253 (2003). https://doi.org/10.1016/S0266-3538(03)00178-7 
[75] Rodríguez-Tobías H., Morales G., Grande D.: Comprehensive review on electrospinning techniques as versatile approaches toward antimicrobial biopolymeric composite fibers. Materials Science and Engineering: C, 101, 306-322 (2019).

https://doi.org/10.1016/j.msec.2019.03.099

[76] Braga N. F., Vital D. A., Guerrini L. M., Lemes A. P., Formaggio D. M. D., Tada D. B., Arantes T. M., Cristovan F. H.: $\mathrm{PHBV}_{-\mathrm{TiO}}$ mats prepared by electrospinning technique: Physico-chemical properties and cytocompatibility. Biopolymers, 109, e23120 (2018). https://doi.org/10.1002/bip.23120

[77] Abedi A., Hasanzadeh M., Tayebi L.: Conductive nanofibrous chitosan/PEDOT:PSS tissue engineering scaffolds. Materials Chemistry and Physics, 237, 121882 (2019). https://doi.org/10.1016/j.matchemphys.2019.121882

[78] Ashraf R., Sofi H. S., Akram T., Rather H. A., Abdal-hay A., Shabir N., Vasita R., Alrokayan S. H., Khan H. A., Sheikh F. A.: Fabrication of multifunctional cellulose/ $\mathrm{TiO}_{2} / \mathrm{Ag}$ composite nanofibers scaffold with antibacterial and bioactivity properties for future tissue engineering applications. Journal of Biomedical Materials Research Part A, 108, 947-962 (2020).

https://doi.org/10.1002/jbm.a.36872

[79] Fang Y., Zhu X., Wang N., Zhang X., Yang D., Nie J., Ma G.: Biodegradable core-shell electrospun nanofibers based on PLA and $\gamma$-PGA for wound healing. European Polymer Journal, 116, 30-37 (2019). https://doi.org/10.1016/j.eurpolymj.2019.03.050

[80] De-Paula M. M. M., Afewerki S., Viana B. C., Webster T. J., Lobo A. O., Marciano F. R.: Dual effective coreshell electrospun scaffolds: Promoting osteoblast maturation and reducing bacteria activity. Materials Science and Engineering: C, 103, 109778 (2019).

https://doi.org/10.1016/j.msec.2019.109778

[81] Vogt L., Rivera L. R., Liverani L., Piegat A., El Fray M., Boccaccini A. R.: Poly(E-caprolactone)/poly(glycerol sebacate) electrospun scaffolds for cardiac tissue engineering using benign solvents. Materials Science and Engineering: C, 103, 109712 (2019).

https://doi.org/10.1016/j.msec.2019.04.091

[82] Liverani L., Killian M. S., Boccaccini A. R.: Fibronectin functionalized electrospun fibers by using benign solvents: Best way to achieve effective functionalization. Frontiers in Bioengineering and Biotechnology, 7, 68 (2019).

https://doi.org/10.3389/fbioe.2019.00068

[83] Xu T., Yao Q., Miszuk J. M., Sanyour H. J., Hong Z., Sun H., Fong H.: Tailoring weight ratio of PCL/PLA in electrospun three-dimensional nanofibrous scaffolds and the effect on osteogenic differentiation of stem cells. Colloids and Surfaces B: Biointerfaces, 171, 3139 (2018).

https://doi.org/10.1016/j.colsurfb.2018.07.004
[84] Xu T., Miszuk J. M., Zhao Y., Sun H., Fong H.: Electrospun polycaprolactone 3D nanofibrous scaffold with interconnected and hierarchically structured pores for bone tissue engineering. Advanced Healthcare Materials, 4, 2238-2246 (2015). https://doi.org/10.1002/adhm.201500345

[85] Xu T., Ding Y., Liang Z., Sun H., Zheng F., Zhu Z., Zhao Y., Fong H.: Three-dimensional monolithic porous structures assembled from fragmented electrospun nanofiber mats/membranes: Methods, properties, and applications. Progress in Materials Science, 112, 100656 (2020). https://doi.org/10.1016/j.pmatsci.2020.100656

[86] Miszuk J. M., Xu T., Yao Q., Fang F., Childs J. D., Hong Z., Tao J., Fong H., Sun H.: Functionalization of PCL-3D electrospun nanofibrous scaffolds for improved BMP2-induced bone formation. Applied Materials Today, 10, 194-202 (2018). https://doi.org/10.1016/j.apmt.2017.12.004

[87] Hu S., Chen H., Zhou X., Chen G., Hu K., Cheng Y., Wang L., Zhang F.: Thermally induced self-agglomeration 3D scaffolds with BMP-2-loaded core-shell fibers for enhanced osteogenic differentiation of rat adiposederived stem cells. International Journal of Nanomedicine, 13, 4145-4155 (2018). https://doi.org/10.2147/IJN.S167035

[88] Xu T., Liang Z., Ding B., Feng Q., Fong H.: Polymer blend nanofibers containing polycaprolactone as biocompatible and biodegradable binding agent to fabricate electrospun three-dimensional scaffolds/structures. Polymer, 151, 299-306 (2018).

https://doi.org/10.1016/j.polymer.2018.07.074

[89] Pina S., Ribeiro V. P., Paiva O. C., Correlo V. M., Oliveira J. M., Reis R. L.: Tissue engineering scaffolds: Future perspectives. in 'Handbook of tissue engineering scaffolds' (eds.: Mozafari M., Sefat F., Atala A.) Woodhead, Sawston, 165-185 (2019). https://doi.org/10.1016/B978-0-08-102563-5.00009-5

[90] Xie Z., Gao M., Lobo A. O., Webster T. J.: 3D bioprinting in tissue engineering for medical applications: The classic and the hybrid. Polymers, 12, 1717 (2020). https://doi.org/10.3390/polym12081717

[91] Saygili E., Dogan-Gurbuz A. A., Yesil-Celiktas O., Draz M. S.: 3D bioprinting: A powerful tool to leverage tissue engineering and microbial systems. Bioprinting, 18, e00071 (2020). https://doi.org/10.1016/j.bprint.2019.e00071

[92] Singh D.: 3D bioprinting for scaffold fabrication. in '3D bioprinting for reconstructive surgery' (eds.: Thomas D., Jessop Z., Whitaker I.) Woodhead, Sawston, 89-123 (2018). https://doi.org/10.1016/B978-0-08-101103-4.00007-7

[93] Nikolova M. P., Chavali M. S.: Recent advances in biomaterials for 3D scaffolds: A review. Bioactive Materials, 4, 271-292 (2019).

https://doi.org/10.1016/j.bioactmat.2019.10.005 
[94] Mukherjee P., Rani A., Saravanan P.: Polymeric materials for 3D bioprinting. in '3D printing technology in nanomedicine' (eds.: Ahmad N., Gopinath P., Dutta R.) Elsevier, Amsterdam, 63-81 (2019). https://doi.org/10.1016/B978-0-12-815890-6.00004-9

[95] Kolesky D. B., Truby R. L., Gladman A. S., Busbee T. A., Homan K. A., Lewis J. A.: 3D bioprinting of vascularized, heterogeneous cell-laden tissue constructs. Advanced Materials, 26, 3124-3130 (2014). https://doi.org/10.1002/adma.201305506

[96] Duan B., Kapetanovic E., Hockaday L. A., Butcher J. T.: Three-dimensional printed trileaflet valve conduits using biological hydrogels and human valve interstitial cells. Acta Biomaterialia, 10, 1836-1846 (2014). https://doi.org/10.1016/j.actbio.2013.12.005

[97] Lee J-S., Hong J. M., Jung J. W., Shim J-H., Oh J-H., Cho D-W.: 3D printing of composite tissue with complex shape applied to ear regeneration. Biofabrication, 6, 024103 (2014) https://doi.org/10.1088/1758-5082/6/2/024103

[98] Zhang S., Wang H.: Current progress in 3D bioprinting of tissue analogs. SLAS Technology, 24, 70-78 (2019). https://doi.org/10.1177/2472630318799971

[99] Masaeli E., Forster V., Picaud S., Karamali F., NasrEsfahani M. H., Marquette C.: Tissue engineering of retina through high resolution 3-dimensional inkjet bioprinting. Biofabrication, 12, 025006 (2020). https://doi.org/10.1088/1758-5090/ab4a20

[100] Schipani R., Scheurer S., Florentin R., Critchley S. E., Kelly D. J.: Reinforcing interpenetrating network hydrogels with 3D printed polymer networks to engineer cartilage mimetic composites. Biofabrication, 12, 035011 (2020).

https://doi.org/10.1088/1758-5090/ab8708
[101] Hakobyan D., Médina C., Dusserre N., Stachowicz M-L., Handschin C., Fricain J-C., Guillermet-Guibert J., Oliveira H.: Laser-assisted 3D bioprinting of exocrine pancreas spheroid models for cancer initiation study. Biofabrication, 12, 035001 (2020). https://doi.org/10.1088/1758-5090/ab7cb8

[102] Combellack E., Jessop Z. M., Whitaker I. S.: The commercial 3D bioprinting industry. in ' $3 \mathrm{D}$ bioprinting for reconstructive surgery' (eds.: Thomas D. J., Jessop Z. M., Whitaker I. S.) Woodhead, Sawston, 413-421 (2018). https://doi.org/10.1016/B978-0-08-101103-4.00029-6

[103] Hakimi N., Cheng R., Leng L., Sotoudehfar M., Ba P. Q., Bakhtyar N., Amini-Nik S., Jeschke M. G., Günther A.: Handheld skin printer: In situ formation of planar biomaterials and tissues. Lab on a Chip, 18, 14401451 (2018). https://doi.org/10.1039/C7LC01236E

[104] Gu Z., Fu J., Lin H., He Y.: Development of 3D bioprinting: From printing methods to biomedical applications. Asian Journal of Pharmaceutical Sciences, 15, 529-557 (2020). https://doi.org/10.1016/j.ajps.2019.11.003

[105] Wahid F., Khan T., Hussain Z., Ullah H.: Nanocomposite scaffolds for tissue engineering; Properties, preparation and applications. in 'Applications of Nanocomposite Materials in Drug Delivery' (eds.: Inamuddin, Asiri A. M., Mohammad A.) Woodhead, Sawston, 701-735 (2018). https://doi.org/10.1016/B978-0-12-813741-3.00031-5

[106] Zhang Y., Zhou D., Chen J., Zhang X., Li X., Zhao W., $\mathrm{Xu}$ T.: Biomaterials based on marine resources for 3D bioprinting applications. Marine Drugs, 17, 555 (2019). https://doi.org/10.3390/md17100555 